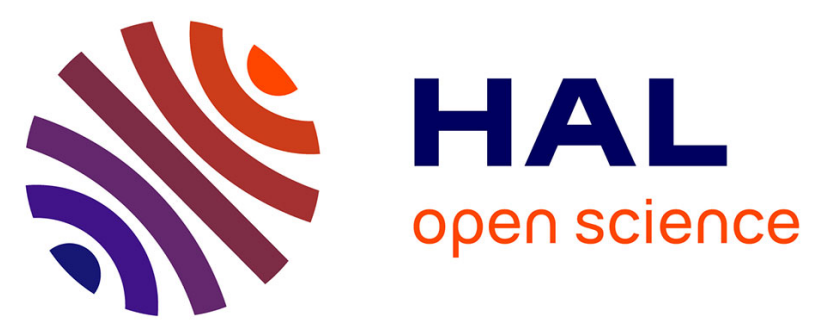

\title{
Theoretical Study of the 15- and 17-Electron Structures of Cyclopentadienylchromium(III) and Cyclopentadienylmolybdenum(III) Complexes. Dichloride and Dimethyl Compounds
}

\author{
Ivo Cacelli, D. Webster Webster Keogh, Rinaldo Poli, Antonio Rizzo
}

\section{To cite this version:}

Ivo Cacelli, D. Webster Webster Keogh, Rinaldo Poli, Antonio Rizzo. Theoretical Study of the 15and 17-Electron Structures of Cyclopentadienylchromium(III) and Cyclopentadienylmolybdenum(III) Complexes. Dichloride and Dimethyl Compounds. Journal of Physical Chemistry A, 1997, 101 (50), pp.9801-9812. 10.1021/jp972920i . hal-03309706

\section{HAL Id: hal-03309706 https://hal.science/hal-03309706}

Submitted on 30 Jul 2021

HAL is a multi-disciplinary open access archive for the deposit and dissemination of scientific research documents, whether they are published or not. The documents may come from teaching and research institutions in France or abroad, or from public or private research centers.
L'archive ouverte pluridisciplinaire HAL, est destinée au dépôt et à la diffusion de documents scientifiques de niveau recherche, publiés ou non, émanant des établissements d'enseignement et de recherche français ou étrangers, des laboratoires publics ou privés. 
Submitted to J. Phys. Chem. 8/97

\section{Theoretical study of the 15- and 17-electron structures of cyclopentadienylchromium(III) and cyclopentadienylmolybdenum(III) complexes. Dichloride and dimethyl compounds.}

\section{Ivo Cacelli, ${ }^{\dagger}$}

Scuola Normale Superiore, Piazza dei Cavalieri 7, I-56126, Pisa, Italy

\section{Webster Keogh,}

Department of Chemistry and Biochemistry, University of Maryland, College Park, MD 20742, USA

\section{Rinaldo Poli, $\$$}

Laboratoire de Synthèse et d'Electrosynthèse Organométallique, Université de Bourgogne, Faculté des Sciences "Gabriel", 6 Boulevard Gabriel, F-21100, Dijon, France

\section{Antonio Rizzo $\$$}

Istituto di Chimica Quantistica ed Energetica Molecolare del Consiglio Nazionale delle Ricerche, Via Risorgimento 35, I-56126 Pisa, Italy

\footnotetext{
${ }^{\dagger}$ E-mail: ivo@hal.icqem.pi.cnr.it

* Present address: Los Alamos National Laboratory, CST-7, MS G739, Los Alamos, NM 87545, USA. E-mail: wkeogh@lanl.gov

\$E-mail:poli@u-bourgogne.fr

$\S$ Corresponding author. E-mail: rizzo@hal.icqem.pi.cnr.it
} 


\begin{abstract}
The structure and the energetics of the model systems $\mathrm{CpMX} 2\left(\mathrm{PH}_{3}\right)+\mathrm{PH}_{3}$ $\mathrm{CpMX}_{2}\left(\mathrm{PH}_{3}\right)_{2}\left(\mathrm{Cp}=\right.$ cyclopentadienyl; $\left.\mathrm{M}=\mathrm{Cr}, \mathrm{Mo} ; \mathrm{X}=\mathrm{Cl}, \mathrm{CH}_{3}\right)$ are studied by performing Møller-Plesset Second Order (MP2) and Density Functional Theory (DFT) calculations. Extended basis sets are employed in the geometry optimizations. The results indicate that the structural preference can be traced back to the competition between electron pairing stabilization and M-P bond dissociation energy along the spin doublet surface. At all levels of calculations, the energy splitting, a measure of the cost of pairing the electron during the promotion process from the quartet ground state to the excited doublet state for $\mathrm{CpCrX} 2\left(\mathrm{PH}_{3}\right)$, is found to be on the average $15-20 \mathrm{kcal} /$ mole greater than the energy gain associated with the formation of the new $\mathrm{Cr}-\mathrm{PH}_{3}$ bond along the spin doublet surface. For the analogous Mo chloride system the reverse appears to be true, the products with higher coordination being energetically favored by $10-12 \mathrm{kcal} /$ mole. These data are in agreement with experimental evidences.
\end{abstract}




\section{Introduction}

Coordination compounds containing soft carbon-based, $\pi$-acidic ligands are most commonly found in low oxidation states, where the strongly covalent metal-ligand interactions typically enforce the 18 -electron rule and a spin-paired ground state. The formation of these bonds is energetically more favored than the spin pairing on the atomic $d^{n}$ configuration. Qualitative observations, however, indicate a more delicate balance between these two energetic stabilizations in higher oxidation state complexes. Experimentally relevant systems have seldom been investigated by computational methods. ${ }^{1}$

Systems that present a particularly interesting structural difference are the halfsandwich cyclopentadienyl $(\mathrm{Cp})$ complexes of the Group 6 metals $\mathrm{Cr}$ and Mo in the oxidation state III. While it is experimentally established that the $\mathrm{Cr}(\mathrm{III})$ complexes always adopt a "three-legged piano stool" structure with a $\mathrm{S}=3 / 2$ ground state [types $\mathrm{CpCrX}_{3}^{-}, \mathrm{CpCrX}_{2} \mathrm{~L}$, $\mathrm{CpCrXL}_{2}{ }^{+}$or $\mathrm{CpCrL}_{3}{ }^{2+}$, where $\mathrm{X}=1$-electron ligand and $\mathrm{L}=2$-electron ligand] ${ }^{2}$ the corresponding $\mathrm{Mo}(\mathrm{III})$ complexes always show a "four-legged piano stool" structure [types

$\mathrm{CpMoX}_{2} \mathrm{~L}_{2}, \mathrm{CpMoXL}_{3}{ }^{+}$and $\left.\mathrm{CpMoL}_{4}{ }^{2+}\right]$ and a $\mathrm{S}=1 / 2$ ground state. ${ }^{3}$ In the valence-electron formalism, one can say that $\mathrm{Cr}$ (III) prefers the 15-electron arrangement, with 12-electrons being donated by the ligand set and three additional electrons occupying the metal-based orbitals (related to the $t_{2 g}$ set in octahedral symmetry) in a parallel fashion, to give rise to a spin quartet ground state. Mo(III) forms instead 17-electron complexes, in which the additional metal-ligand interaction relative to the $\mathrm{Cr}$ (III) complexes forces the electron pairing in order to vacate the necessary orbital.

In a recent experimental study, ${ }^{4}$ adducts of the $\mathrm{CpCrX}_{2}\left(\mathrm{X}=\mathrm{Cl}, \mathrm{CH}_{3}\right)$ fragments with a series of bidentate ligands, i.e. $\mathrm{Me}_{2} \mathrm{PCH}_{2} \mathrm{PMe}_{2}(\mathrm{dmpm}), \mathrm{Me}_{2} \mathrm{PCH}_{2}-\mathrm{CH}_{2} \mathrm{PMe}_{2}$ (dmpe) and $\mathrm{Ph}_{2} \mathrm{PCH}_{2} \mathrm{CH}_{2} \mathrm{PPh}_{2}$ (dppe) $\left(\mathrm{Me}=\mathrm{CH}_{3}\right)$, were described. It was noted that the presence of a second donor atom in the neutral ligand and the consequent entropic "chelate effect" is not sufficient to win the resistance of the $\mathrm{Cr}$ (III) center to the electron pairing process. It was also 
pointed out that the difference in sterics (the smaller size of $\mathrm{Cr}^{3+}$ with respect to $\mathrm{Mo}^{3+}$ ) and trends in the metal-ligand bond strengths (the general increase of the metal to ligand bond dissociation energy upon descending a group of transition metals ${ }^{5}$ ) cannot fully explain this behavior.

This type of problem seems to be well suitable for a computational analysis. Modern computational chemistry has developed methods and algorithms which make it more and more powerful and close to the needs and problems of the everyday experiment. Quite sophisticate approaches as for example Møller-Plesset Perturbation Theory (MPx, $\mathrm{x}=2,3, \ldots){ }^{6}$ or the various applications of Density Functional Theory (DFT), ${ }^{7}$ can almost routinely be applied to obtain reliable structural and energetic data in "large" molecular systems. The use of so-called “direct" techniques, exploiting the rapid advances in the architecture of modern CPU's, combined with the fast decrease in the cost of mass memory, makes the use of ab-initio Computational Chemistry for molecular systems with hundredths or even thousands of electrons affordable, even from "small" desktop and personal computers. In particular, the study of the transition metal systems with $a b$-initio ${ }^{8}$ or Density Functional Theory ${ }^{9}$ techniques has seen a flourishing of interest in recent years.

In a preliminary communication, ${ }^{10}$ the results of DFT (BLYP) calculations with full geometry optimization on the $\mathrm{PH}_{3}$ addition to $\mathrm{CpMCl}_{2}\left(\mathrm{PH}_{3}\right)$ have been presented. Quite different results for $\mathrm{M}=\mathrm{Cr}$ and $\mathrm{Mo}$, in accord with the experimentally established stability trends were obtained. The calculations point to the paramount importance of electron pairing energy: a sizable amount of energy must be spent to promote the ground state ${ }^{4} \mathrm{~A}$ " $\mathrm{CpCrCl}_{2}\left(\mathrm{PH}_{3}\right)$ to the ${ }^{2} \mathrm{~A}$ ' excited state, and only a fraction is regained upon formation of the second $\mathrm{Cr}-\mathrm{PH}_{3}$ bond. The cost of pairing the electrons in $\mathrm{CpMoCl}_{2}\left(\mathrm{PH}_{3}\right)$, on the other hand, is much less and the bond formation energy along the spin doublet surface far larger. The relevance of electron pairing energy as a stabilizing factor for the general class of open-shell organometallics was thus pointed out. 
In this paper we extend the analysis by refining the results of Ref. [10] and by extending the study to the dimethyl derivative of the cyclopentadienyl chromium system. There is experimental evidence that the corresponding dimethyl derivatives of molybdenum are unstable, rapidly decomposing with elimination of a methyl radical. ${ }^{11}$ The use of extended basis sets, which include diffuse and polarization functions to improve the description of the metal-ligand bonds, and a comparison of different electron correlated approaches (ab-initio vs. "semi-empirical", MP2 vs. DFT) guarantees a good stability and reliability of the results. Geometries were fully optimized. The resulting structural parameters, together with the energy differences, allow to draw conclusions on the relative stability of the systems under study.

The techniques used here to gain information on the electronic structure and geometrical arrangement of transition metal complexes are quite routinely employed by several groups. The applications of DFT to the study of transition metal complexes are for instance widely exploited by Ziegler and his coworkers, also with emphasis on properties. ${ }^{12}$ The literature on the use of Møller-Plesset Perturbation Theory in the realm of computational chemistry is vast, and it would be difficult and impractical to select here relevant and pertinent references. See anyhow Refs. 8. Some recent work by Bauschlicher and coworkers (see e.g. Refs. 13), by Morokuma and his group (see, e.g. Refs. 14) and by Schwarz and collaborators (see e.g. Refs. 15) bear some similarities to the computational scheme employed here. As examples of very recent papers on topics quite close to those discussed here see Refs. 16, 17. $\mathrm{Su}$ and $\mathrm{Chu}^{16}$ studied the addition of $\mathrm{CH}_{4}$ to some 16-electron cyclopentadienyl complexes of the VIII group transition metals ( $\mathrm{Ru}, \mathrm{Os}, \mathrm{Rh}, \mathrm{Ir}, \mathrm{Pd}, \mathrm{Pt})$, resorting to a computational approach similar to ours. They employed MP2, MP4 and DFT-B3LYP geometry optimization schemes, showing a slight preference for the latter, although qualitatively correct results could also be obtained already with MP2. Schmid ${ }^{17}$ used both MP2 and DFT-LDA to study rhodiumcatalyzed hydroformylation reactions, involving the dissociation of phosphines. According to their observations, DFT proves to be very efficient in furnishing accurate geometries and bond 
energies at a fraction of the cost of more sophisticated - CCSD(T) - methods, while MP2 overestimates bond energies in some cases by as much as $100 \%$.

\section{Computational details}

All the calculations were performed using GAUSSIAN 94. ${ }^{18}$ Møller-Plesset SecondOrder (MP2) ${ }^{19}$ complete geometry optimizations were performed employing the LanL2DZ basis set, which includes both Dunning and Hay's D95 sets for $\mathrm{H}$ and $\mathrm{C}^{20}$ and the relativistic Electron Core Potential (ECP) sets of Hay and Wadt for the heavy atoms. ${ }^{21}$ Electrons outside the core were all those of $\mathrm{H}$ and $\mathrm{C}$ atoms, the $\mathrm{n} s, \mathrm{n} p, \mathrm{n} d$ and $(\mathrm{n}+1) s$ electrons in $\mathrm{Cr}(\mathrm{n}=3)$ and Mo $(\mathrm{n}=4)$ and the $3 s, 3 p$ electrons in Cl, P. Calculations were also performed with the smaller LanL1DZ set, where the $\mathrm{n} s, \mathrm{n} p$ orbitals $(\mathrm{n}=3, \mathrm{Cr} ; \mathrm{n}=4, \mathrm{Mo})$, which are of radial extension comparable to that of the outer $d$ shell orbitals, are left in the core.

The LanL2DZ set was also employed to perform complete geometry optimization with a Density Functional Theory (DFT) approach. The Becke (B) exchange functional, ${ }^{22}$ including gradient of the density corrections to Slater's Local Spin Density exchange ${ }^{23}$ together with Lee, Yang and Parr (LYP) correlation functional ${ }^{24}$ were employed. In order to improve our description and to obtain as quantitative as possible estimates for the energies and geometries, the LanL2DZ basis set was further gradually extended, by decontracting inner functions and adding diffuse and polarization correlation functions, to reach our largest set (labeled "Basis V' here) arranged as follows: the $s$, inner $p$ and $d$ function on the heavy atoms of the LanL2DZ set were decontracted, thus yielding a valence $<5 s 4 p 3 d>$ set. The innermost $p$ functions in the expansion sets for $\mathrm{C}, \mathrm{P}$ and $\mathrm{Cl}$ were also decontracted. Two $d$ functions (exponents 1.2, 0.53) were added to the basis for $\mathrm{C}$, a $p$ (exponent 1.21) and two $d$ (exponents 0.88, 0.37) functions were added to the set for $\mathrm{P}$, and a $p$ (exponent 2.0) and two $d$ (exponents 1.1, 0.5) functions were added to the set for $\mathrm{Cl}$. Basis $\mathrm{V}$ was employed to perform DFT geometry optimizations on the structures of interest. In this case the three parameter form of the Becke, 
Lee, Yang and Parr functional (B3LYP) ${ }^{25}$ including exact-exchange terms, was also used. Becke's three parameter semi-empirical exchange functional was originally obtained by fitting the atomization energies, ionization potentials and proton affinities in the systems of the so-called G1 database, ${ }^{26}$ a group of atomic and molecular systems of the first and second row, and it is nowadays widely employed and singled out among the several density functionals available in the literature. Its use for the study of transition metal complexes, where it proves to be reliable both in the geometry optimization and in energy calculations, has become more and more customary, see for instance Ref. 14b and references therein, and the very recent Ref. 16 . On the other hands, it has been observed that B3LYP reveals "a systematic shortcoming (...) in the description of weakly bound complexes", ${ }^{15 b}$ where binding energies can be often overestimated. A comparison of the results obtained in both the BLYP and B3LYP approximations will be made later in the paper. Due to the substantial equivalence of the results obtained with the MP2 and DFT approaches and to the higher computational cost of MP2 vs. DFT, no MP2 geometry optimization was carried out with Basis V. The five different geometry optimization calculations will hereafter be labeled as L1-MP2 (Basis LanL1DZ, MP2), L2-MP2 (Basis LanL2DZ, MP2), L2-BLYP (Basis LanL2DZ, DFTBLYP), and V-BLYP (Basis V, DFT-BLYP) and V-B3LYP (Basis V, DFT-B3LYP).

A $\mathrm{C}_{s}$ symmetry arrangement was imposed. For the study of the $\mathrm{PH}_{3}$ addition to form the 17-electron four-legged piano-stool species, of the two possible configurations for the 17electron $\mathrm{CpCrX}_{2}\left(\mathrm{PH}_{3}\right)_{2}$ (cis and trans with respect to the four ligands defining the legs of the "stool"), only the trans configuration was considered, since this is the only observed structure for the analogous Mo(III) complexes when monodentate ligands are utilized. ${ }^{3}$ We distinguish systems having symmetry equivalent chlorine (I) or phosphine (II) ligands for the 17-electron species. Both possible conformations of the 15-electron $\mathrm{CrMX}_{2}\left(\mathrm{PH}_{3}\right)$ system having an "eclipsed" (III) or "staggered" (IV) conformation, respectively, have been used for the calculations (Chart 1). The difference in energy between these two structures was found to be 
in general quite small, see below. Only results for the lowest energy conformation are reported in the discussion and in the tables.

\section{Chart 1.}

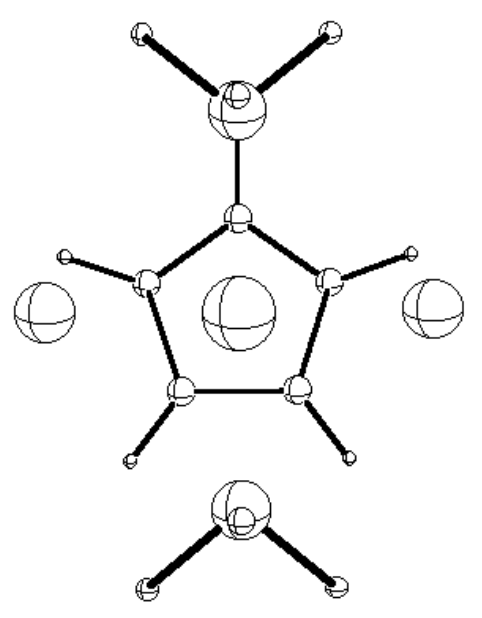

I

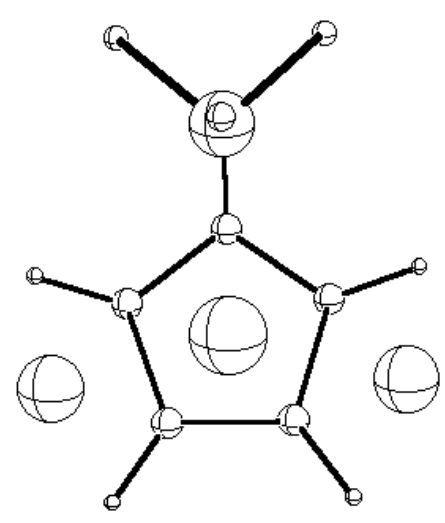

III

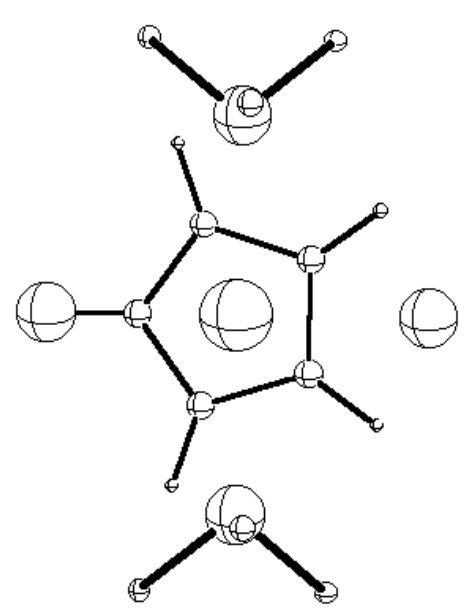

II

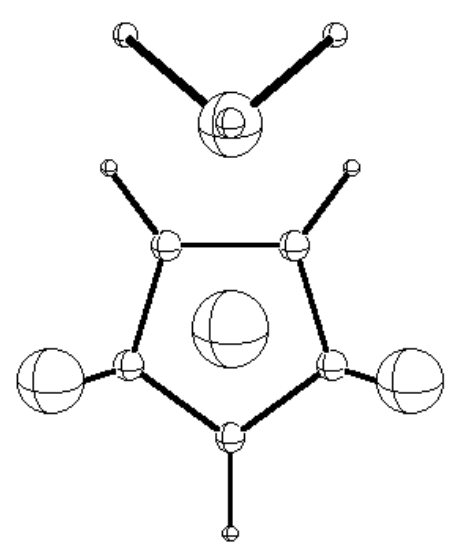

IV

The mean values of the spin of the electronic wavefunctions, which are not exact eigenstates of the $\mathrm{S}^{2}$ operator for unrestricted calculations, were considered suitable to identify unambiguously the spin state. Spin contamination was carefully monitored and the energies shown in the next sections correspond to unrestricted MP2 or unrestricted BLYP, B3LYP calculations. Spin contamination was generally smaller in the DFT than in the MP2 
calculations, with the first order perturbed wavefunction in the latter case showing roughly the same degree of spin contamination as the zero $^{\text {th }}$-order reference wavefunction. An exception was the 15-electron $\mathrm{CpCr}\left(\mathrm{CH}_{3}\right)_{2}\left(\mathrm{PH}_{3}\right)$ system in the excited doublet state, where MP2 and DFT optimizations lead to states with different occupation numbers for the $\alpha$ and $\beta$ spin-orbitals, as discussed in detail below.

The calculations were carried out on the RISC $6000590 \mathrm{H}$ workstation of the ICQEM/CNR in Pisa and on the DEC/Alphastation 250 at the University of Maryland in College Park. Each geometry optimization with our largest basis set required several hours of CPU. In this respect the chromium systems proved to be much more delicate and demanding than the molybdenum ones. They often needed careful monitoring of the convergence patterns and special care in the choice of the starting geometry.

\section{Results}

Calculations were carried out on the model systems $\mathrm{CpCrX}_{2}\left(\mathrm{PH}_{3}\right)_{\mathrm{n}}(\mathrm{n}=1,2 ; \mathrm{X}=\mathrm{Cl}$ and $\left.\mathrm{CH}_{3}\right)$ and $\mathrm{CpMoCl}_{2}\left(\mathrm{PH}_{3}\right)_{\mathrm{n}}(\mathrm{n}=1,2)$. For the 15-electron $(\mathrm{n}=1)$ systems, the energies and structures were determined for both the spin doublet and the spin quartet states. The energy of the doublet 17-electron $(\mathrm{n}=2)$ system was calculated with respect to the 15 -electron system and $\mathrm{PH}_{3}$ at infinite distance. No transition states or reaction paths were actually determined. To obtain the relative energies, a geometry optimization of the free phosphine ligand was carried out. The geometry was fully optimized both at the MP2 (L1-MP2, L2-MP2) and DFT (L2-BLYP, V-BLYP, V-B3LYP) levels of approximation for each system. Complete structural and energetic data are available in tabular form from the authors for all five calculations. For the sake of conciseness, we report in the Tables only the results obtained with our largest basis set (Basis V), while relevant parameters for all calculations are discussed with the aid of appropriate Figures. 
A. Chloride systems. Tables 1 and 2 summarize the results obtained using our largest basis set (Basis V) both at the DFT-BLYP and DFT-B3LYP levels of approximation for the energies and structural parameters of the 15-electron $\left({ }^{2} \mathrm{~A}\right.$ ' and $\left.{ }^{4} \mathrm{~A} "\right) \mathrm{CpCrCl}_{2}\left(\mathrm{PH}_{3}\right)$ and $\mathrm{CpMoCl}_{2}\left(\mathrm{PH}_{3}\right)$ species and of the corresponding 17-electron $\left({ }^{2} \mathrm{~A}^{\prime}\right) \mathrm{CpCrCl}_{2}\left(\mathrm{PH}_{3}\right)_{2}$ and $\mathrm{CpMoCl}_{2}\left(\mathrm{PH}_{3}\right)_{2}$.

Absolute energies (valence electron only - the contribution of the electrons in the ECP shells is omitted) and relative energies for the system $\mathrm{CpMCl}_{2}\left(\mathrm{PH}_{3}\right)+\mathrm{PH}_{3}$

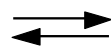
$\mathrm{CpMCl}_{2}\left(\mathrm{PH}_{3}\right)_{2}$ are reported. Average computed distances and angles are shown for symmetry non equivalent atoms, with the deviation from average given in parentheses. The results for only one of the two possible conformations (I or II for 17-electron systems, III or IV for 15electron systems) with respect to rotation of the cyclopentadienyl ring, i.e. that of lowest energy for each case, is reported. In the case of $\mathrm{Cr}$, the ${ }^{4} \mathrm{~A} " 15$-electron eclipsed conformation (III) is energetically favored relative to the staggered conformation (IV) by less than a tenth of a $\mathrm{mH}(0.05 \mathrm{kcal} / \mathrm{mole}$, estimated at the L2-BLYP level of approximation), while the two conformations are practically isoenergetic for the ${ }^{2} \mathrm{~A}^{\prime}$ state. With a few remarkable exceptions (which will be briefly discussed later) the same applies to all systems studied here. Thus, the conclusions of our study are generally not affected by the rotational conformation of the cyclopentadienyl ring. Experimentally, the rapid rotation of $\mathrm{Cp}$ rings around the $\mathrm{Cp}-\mathrm{M}$ axis in compounds of low symmetry generates a single resonance in the ${ }^{1} \mathrm{H}$ and ${ }^{13} \mathrm{C}$-NMR spectra at all temperatures, indicating a rotation barrier of a few $\mathrm{kcal} / \mathrm{mol}$ at the most. ${ }^{27}$

Experimental structural data with standard deviations from X-ray diffraction studies of relevant compounds are also listed in the Tables for comparison. These are the $\mathrm{CpCrCl}_{2}$ (dmpm) complex for the 15-electron, spin quartet $\mathrm{Cr}$ system ${ }^{4}$ and the $\mathrm{CpMoCl}_{2}\left(\mathrm{PMe}_{3}\right)_{2}$ complex for the 17-electron spin doublet Mo system. ${ }^{3 \mathrm{~b}}$

B. Methyl systems. Table 3 lists both the V-BLYP and V-B3LYP results obtained for the energies and structural parameters of the 15 -electron $\left({ }^{2} \mathrm{~A} "\right.$ and $\left.{ }^{4} \mathrm{~A} "\right) \mathrm{CpCr}\left(\mathrm{CH}_{3}\right)_{2}\left(\mathrm{PH}_{3}\right)$ species and of the corresponding 17-electron doublet $\left({ }^{2} \mathrm{~A}^{\prime}\right) \mathrm{CpCr}\left(\mathrm{CH}_{3}\right)_{2}\left(\mathrm{PH}_{3}\right)_{2}$ system. 
Table 1. Basis V. DFT-optimized geometries and energies of $\mathrm{CpCrCl}_{2}\left(\mathrm{PH}_{3}\right)_{\mathrm{n}}\left(\mathrm{n}=1\right.$ or 2). ${ }^{a}$

\begin{tabular}{|c|c|c|c|c|c|c|c|}
\hline & expt. $^{b}$ & \multicolumn{3}{|c|}{ V-BLYP } & \multicolumn{3}{|c|}{ V-B3LYP } \\
\hline & & \multicolumn{2}{|c|}{ 15-el. eclipsed (III) } & \multirow{2}{*}{$\begin{array}{l}\text { 17-el. (I) } \\
\text { equiv. } \mathrm{Cl}\end{array}$} & \multicolumn{2}{|c|}{ 15-el. eclipsed (III) } & \multirow{2}{*}{$\begin{array}{l}\text { 17-el. (I) } \\
\text { equiv. } \mathrm{Cl}\end{array}$} \\
\hline & & $\mathrm{S}=1 / 2$ & $\mathrm{~S}=3 / 2$ & & $\mathrm{~S}=1 / 2$ & $\mathrm{~S}=3 / 2$ & \\
\hline $\mathrm{Cr}-\mathrm{Cl}$ & $\begin{array}{l}2.281(2) \\
2.295(2)\end{array}$ & 2.270 & 2.283 & 2.415 & 2.261 & 2.278 & 2.401 \\
\hline Cr-P & $2.410(2)$ & 2.399 & 2.476 & $2.422(10)$ & 2.415 & 2.489 & $2.421(6)$ \\
\hline $\mathrm{CNT}-\mathrm{Cr}$ & $1.882(7)$ & 1.877 & 1.949 & 1.880 & 1.866 & 1.929 & 1.874 \\
\hline $\mathrm{Cl}-\mathrm{Cr}-\mathrm{Cl}$ & $100.08(8)$ & 105.12 & 101.78 & 116.26 & 106.20 & 102.08 & 116.50 \\
\hline $\mathrm{Cl}-\mathrm{Cr}-\mathrm{P}$ & $\begin{array}{l}92.80(7) \\
88.59(7)\end{array}$ & 86.46 & 86.53 & $77.36(9)$ & 85.23 & 85.28 & $77.34(4)$ \\
\hline $\mathrm{P}-\mathrm{Cr}-\mathrm{P}$ & & & & 131.02 & & & 130.76 \\
\hline CNT-Cr-Cl & $\begin{array}{l}122.5(2) \\
124.8(2)\end{array}$ & 124.63 & 123.23 & 121.85 & 124.44 & 123.35 & 121.73 \\
\hline CNT-Cr-P & $119.3(2)$ & 116.64 & 125.21 & $114.49(182)$ & 117.58 & 126.56 & $114.62(166)$ \\
\hline Cr-CNT-Cp (plane) & & 85.26 & 89.37 & 85.53 & 86.22 & 89.44 & 86.46 \\
\hline $\bar{E}(\mathrm{au})$ & & -317.95838 & -317.99073 & -326.23068 & -318.21110 & -318.25479 & -326.53127 \\
\hline Relative E (kcal/mol) & & 20.30 & 0 & 13.57 & 27.42 & 0 & 19.06 \\
\hline
\end{tabular}

${ }^{a} \mathrm{E}\left(\mathrm{PH}_{3}\right):-8.26158$ au (V-BLYP), -8.30685 au (V-B3LYP). The 15-electron systems are with the Cp ring in an eclipsed conformation, the 17-electron systems are with two equivalent chlorine ligands. CNT indicates the centroid of the cyclopentadienyl ring. $\mathrm{Cp}$ (plane) indicates the least square plane containing the $\mathrm{Cp}$ ring. Distances in $\AA$, angles in degrees. ${ }^{b} \mathrm{CpCrCl}_{2}(\mathrm{dmpm})$, ref. 4 . 
Table 2. Basis V. DFT optimized geometries and energies of $\mathrm{CpMoCl}_{2}\left(\mathrm{PH}_{3}\right) \mathrm{n}\left(\mathrm{n}=1\right.$ or 2). ${ }^{a}$

\begin{tabular}{|c|c|c|c|c|c|c|c|}
\hline & expt. $^{b}$ & \multicolumn{3}{|c|}{ V-BLYP } & \multicolumn{3}{|c|}{ V-B3LYP } \\
\hline & & \multicolumn{2}{|c|}{ 15-el. staggered (IV) } & \multirow{2}{*}{$\begin{array}{l}\text { 17-el. (II) } \\
\text { equiv. } \mathrm{PH}_{3}\end{array}$} & \multicolumn{2}{|c|}{ 15-el. staggered (IV) } & \multirow{2}{*}{$\frac{17 \text {-el. (II) }}{\text { equiv. } \mathrm{PH}_{3}}$} \\
\hline & & $\mathrm{S}=1 / 2$ & $\mathrm{~S}=3 / 2$ & & $\mathrm{~S}=1 / 2$ & $\mathrm{~S}=3 / 2$ & \\
\hline $\mathrm{Mo}-\mathrm{Cl}$ & $\begin{array}{l}2.468(2) \\
2.474(2)\end{array}$ & 2.391 & 2.413 & 2.515 & 2.388 & 2.404 & 2.501 \\
\hline Mo-P & $\begin{array}{l}2.484(2) \\
2.481(2)\end{array}$ & 2.463 & 2.566 & 2.514 & 2.468 & 2.571 & 2.504 \\
\hline CNT-Mo & $1.938(7)$ & 2.064 & 2.074 & 2.015 & 2.000 & 2.056 & 2.002 \\
\hline Cl-Mo-Cl & $125.14(7)$ & 123.80 & 97.60 & 120.26 & 110.25 & 97.85 & 119.07 \\
\hline Cl-Mo-P & $\begin{array}{l}79.01(6), 79.59(6) \\
80.25(6), 79.41(6)\end{array}$ & 83.23 & 86.05 & $77.86(44)$ & 85.42 & 84.46 & $77.68(37)$ \\
\hline P-Mo-P & $133.66(6)$ & & & 130.02 & & & 130.22 \\
\hline CNT-Mo-Cl & $117.42(3)$ & 113.97 & 123.92 & 119.87(97) & 122.54 & 124.13 & $120.46(75)$ \\
\hline CNT-Mo-P & $113.16(3)$ & 134.90 & 128.09 & 114.99 & 117.87 & 129.80 & 114.89 \\
\hline Mo-CNT-Cp (plane) & & 86.78 & 89.43 & 84.62 & 86.20 & 89.86 & 85.09 \\
\hline$E(\mathrm{au})$ & & -299.14998 & -299.15328 & -307.43115 & -299.42854 & -299.43854 & -307.76178 \\
\hline Relative E (kcal/mol) & & 12.31 & 10.24 & 0 & 16.56 & 10.28 & 0 \\
\hline
\end{tabular}

${ }^{a} \mathrm{E}\left(\mathrm{PH}_{3}\right):-8.26158$ au (V-BLYP), -8.30685 au (V-B3LYP). The 15-electron systems are with the Cp ring in a staggered conformation, the 17-electron systems are with two equivalent phosphine ligands. CNT indicates the centroid of the cyclopentadienyl ring. $\mathrm{Cp}$ (plane) indicates the least square plane containing the $\mathrm{Cp}$ ring. Distances in $\AA$, angles in degrees. ${ }^{b} \mathrm{CpMoCl}_{2}\left(\mathrm{PMe}_{3}\right)_{2}, \mathrm{Ref} 3 \mathrm{~b}$. 
Table 3. Basis V. DFT optimized geometries and energies of $\mathrm{CpCr}\left(\mathrm{CH}_{3}\right)_{2}\left(\mathrm{PH}_{3}\right)_{\mathrm{n}}\left(\mathrm{n}=1\right.$ or 2). ${ }^{a}$

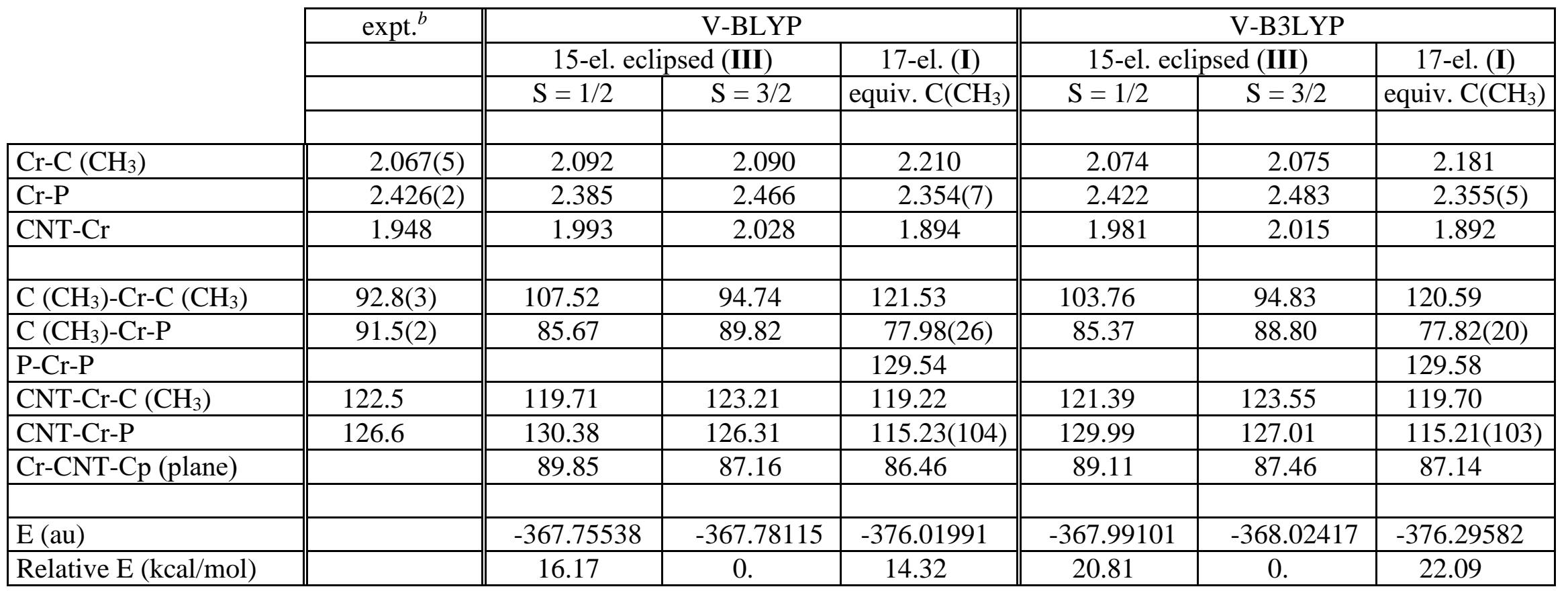

${ }^{a} \mathrm{E}\left(\mathrm{PH}_{3}\right):-8.26158 \mathrm{au}$ (V-BLYP), -8.30685 au (V-B3LYP). The 15-electron systems are with the Cp ring in an eclipsed conformation, the 17-electron systems are with two equivalent methyl ligands. CNT indicates the centroid of the cyclopentadienyl ring. $\mathrm{Cp}(\mathrm{plane})$ indicates the least square plane containing the $\mathrm{Cp}$ ring. Distances in $\AA$, angles in degrees. ${ }^{b} \mathrm{Cp} * \mathrm{Cr}\left(\mathrm{CH}_{3}\right)_{2}\left(\mathrm{PMe}_{3}\right), \mathrm{Cp}^{*}=\mathrm{C}_{5} \mathrm{Me}_{5}, \mathrm{Ref}$. 2 . 
Absolute (valence electrons only) energies and relative energies for the system $\mathrm{CpCr}\left(\mathrm{CH}_{3}\right)_{2}\left(\mathrm{PH}_{3}\right)+\mathrm{PH}_{3} \rightleftarrows \mathrm{CpCr}\left(\mathrm{CH}_{3}\right)_{2}\left(\mathrm{PH}_{3}\right)_{2}$ are reported. The corresponding species involving molybdenum are not thermally stable systems ${ }^{11}$ and were not studied in this occasion. Experimental references for bond and angles were taken in this case from compound $\mathrm{Cp} * \mathrm{Cr}\left(\mathrm{CH}_{3}\right)_{2} \mathrm{P}\left(\mathrm{CH}_{3}\right)_{3}$ system, $\mathrm{Cp}^{*}=\eta^{5}-\mathrm{C}_{5}\left(\mathrm{CH}_{3}\right)_{5}{ }^{2 \mathrm{c}}$ Another relevant crystallographically determined dimethyl compound is $\left[\mathrm{CpCr}\left(\mathrm{CH}_{3}\right)_{2}\right]_{2}(\mu$-dppe $),{ }^{4}$ but severe crystallographic disorder makes this compound less suitable for the comparison of metric parameters.

We stress here that in view of the qualitative agreement of the results obtained in the LanL2DZ basis set with the MP2 and DFT approximations, the large and expensive geometry optimizations runs with Basis V were performed only in the less CPU-intensive DFT approach.

\section{Discussion}

A. Electronic structure. The 15-electron $\mathrm{CpMX}_{2}\left(\mathrm{PH}_{3}\right)$ complexes are calculated to have a spin quartet ground state in each case. This state involves the occupation of three metalcentered orbitals (labeled 1a', 1a" and 2a') by the three unpaired electrons. These three orbitals correspond to the pseudo- $t_{2 \mathrm{~g}}$ set of the ideal isolobal octahedral $\mathrm{ML}_{6}$ complex where three monodentate $\mathrm{L}$ ligands replace the $\mathrm{Cp}$ ring; they also correspond to the three frontier orbitals of the generic $\mathrm{CpML}_{3}$ fragment as described by Albright, Burdett, and Wangbo. ${ }^{28}$ These three orbitals are almost purely metal-based, with only minimal contributions from atomic orbitals of the ligands. There is therefore a very small contribution, according to our calculations, both of the $\mathrm{X}-\mathrm{M} \sigma(<0.1 \%)$ and $\mathrm{X}-\mathrm{M} \pi$-donation $(<0.01 \%)$ in both $\mathrm{Cr}$ and Mo systems.

The doublet 15 -electron state was generally found in the $\left(1 \mathrm{a}^{\prime}\right)^{1}\left(1 \mathrm{a}^{\prime \prime}\right)^{2}$ electronic configuration. A remarkable exception was found for the $\mathrm{CpCr}\left(\mathrm{CH}_{3}\right)_{2}\left(\mathrm{PH}_{3}\right)$ system, where MP2 and DFT produced doublet ground states of different symmetry. The former led to a $\left(1 a^{\prime}\right)^{1}\left(1 a^{\prime \prime}\right)^{2}$ dominated doublet ground state. The doublet ground state wavefunction in the DFT approach corresponds to a $\left(1 \mathrm{a}^{\prime} \beta\right)^{1}\left(1 \mathrm{a}^{\prime \prime} \alpha\right)^{1}\left(2 \mathrm{a}^{\prime} \alpha\right)^{1}$ configuration, where the subscripts were 
appended to distinguish between different spin orbitals. This is due to a near degeneration of the spin-orbitals involved, and it highlights an interesting advantage of DFT vs. MP perturbation theory in these cases, where a perturbative treatment of electronic correlation starting from a single determinant which is nearly degenerate with excited configurations might easily lead into error. Note that the two configurations are in our case of different spatial symmetry, and that they do not interact in the perturbation expansion.

Insight on the electronic structure of the systems under study is given by the analysis of the electron density maps shown in Figures 1 to 3.

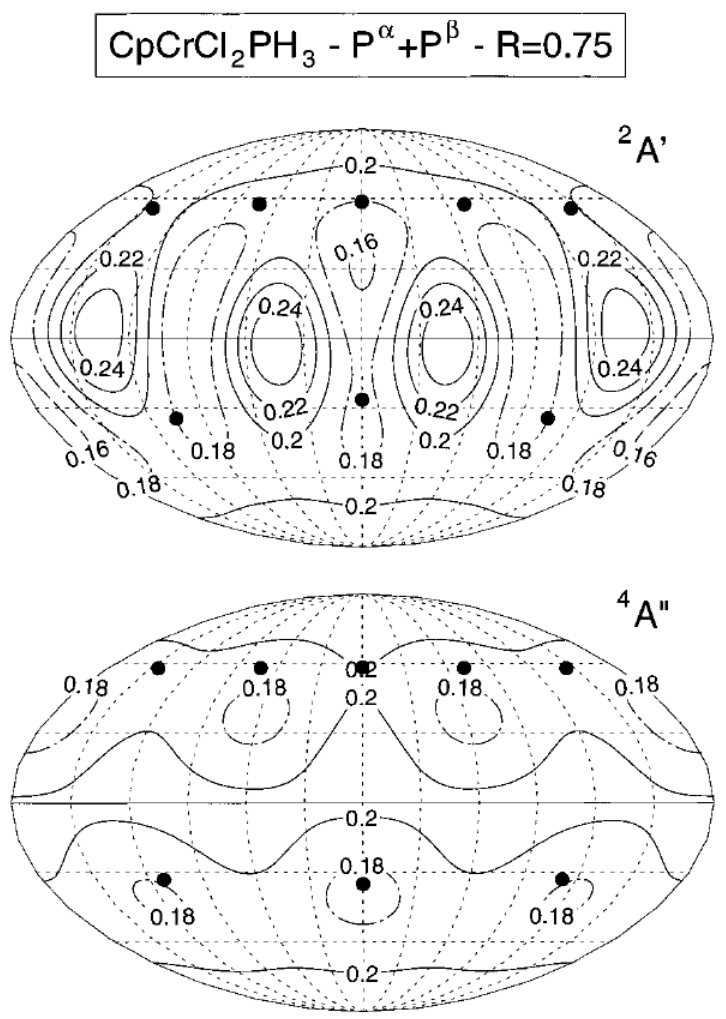

Figure 1 Contour plot of the total electron density (au) obtained using the V-BLYP KohnSham orbitals at a radial distance of $0.75 \AA$ from the metal center in the ${ }^{2} \mathrm{~A}$ ' (top) and ${ }^{4} \mathrm{~A}$ " (bottom) states of $\mathrm{CpCrCl}_{2} \mathrm{PH}_{3}$. The dots represent the projected image of the ligand atoms on the surface of the sphere ( $\mathrm{H}$ atoms neglected). The "parallels" are traced ad intervals of $30^{\circ}$ for the polar angle $\theta$ (from $0^{\circ}$, top, to $180^{\circ}$, bottom); the "meridians" indicate the azimuthal angle $\varphi$ at intervals of $30^{\circ}$ 
in the $0^{\circ}$ to $360^{\circ}$ range. The molecular symmetry plane containing one of the carbon atoms of the $\mathrm{Cp}$ ring, the central metal and the phosphorus (the $x z$ plane) corresponds to the central "meridian".

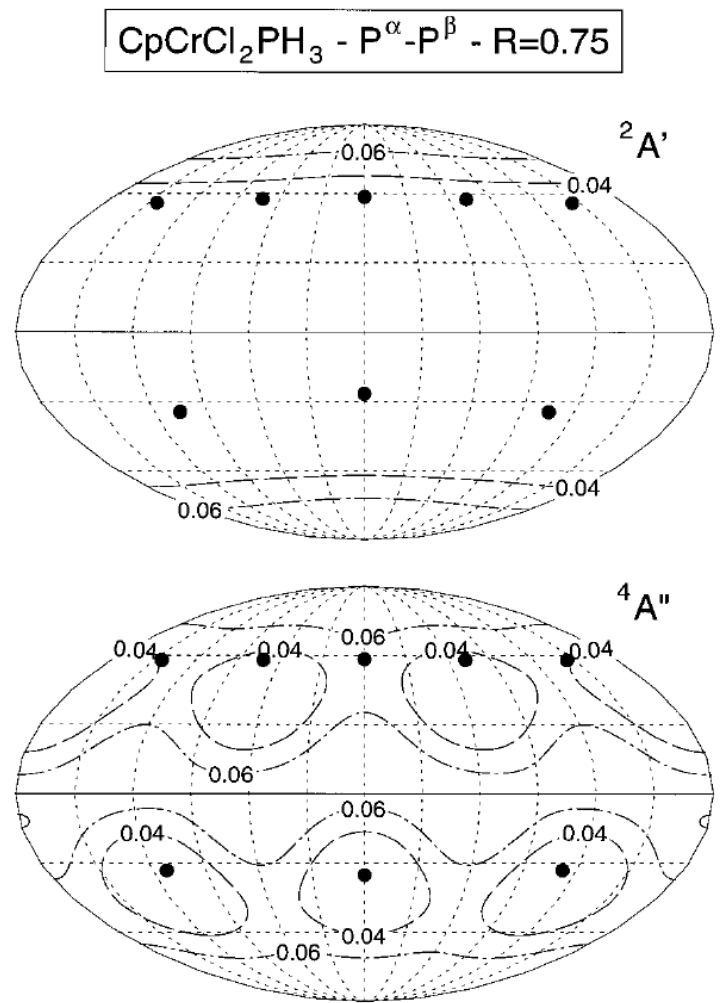

Figure 2 Contour plot of the excess electron spin density (au) obtained using the V-BLYP Kohn-Sham orbitals at a radial distance of $0.75 \AA$ from the metal center in the ${ }^{2} \mathrm{~A}$ ' (top) and ${ }^{4} \mathrm{~A} "$ (bottom) states of $\mathrm{CpCrCl}_{2} \mathrm{PH}_{3}$. Other drawing parameters are as in Figure 1. 


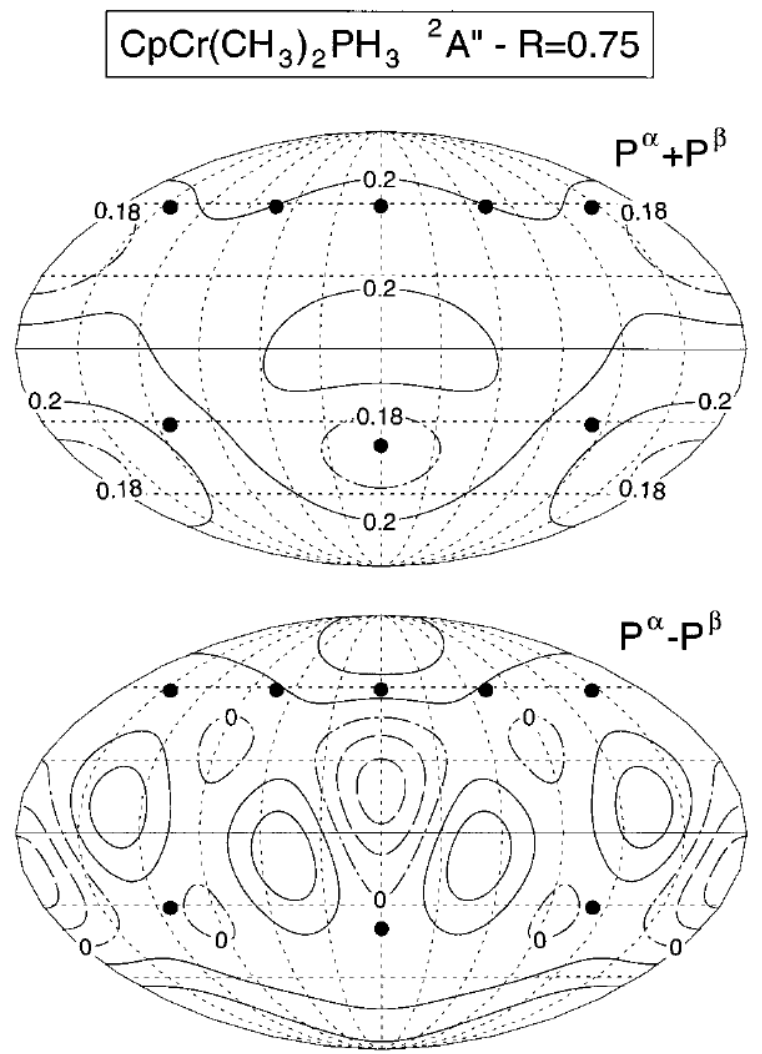

Figure 3 Contour plot of the total (top) and excess (bottom) electron spin density (au) obtained using the V-BLYP Kohn-Sham orbitals at a radial distance of $0.75 \AA$ from the metal center in the ${ }^{2} \mathrm{~A}$ " state of $\mathrm{CpCr}\left(\mathrm{CH}_{3}\right)_{2} \mathrm{PH}_{3}$. In the lower part of the figure, only the zero-density contour lines are labeled. Dashed lines are for negative ( $\beta$ spin excess), full lines for positive ( $\alpha$ spin excess) density. Contour lines are drawn at 0.03 au intervals. Other drawing parameters are as in Figure 1.

The first two figures show projections of the electron density $\left(P^{\alpha}+P^{\beta}\right.$, Figure 1) and excess spin density $\left(P^{\alpha}-P^{\beta}\right.$, Figure 2$)$ on a spherical surface of radius $0.75 \AA$ centered on the $\mathrm{Cr}$ nucleus for the ${ }^{2} \mathrm{~A}$ ' and ${ }^{4} \mathrm{~A}$ " states of $\mathrm{CpCrCl}_{2}\left(\mathrm{PH}_{3}\right)$. The distance corresponds approximately to the radial maximum of the $d$ metal orbitals. The densities were obtained using the Kohn-Sham orbitals ${ }^{29,30}$ of the V-BLYP calculation. The molecular symmetry plane including a carbon atom of the $\mathrm{Cp}$ ring, the metal and the phosphorus is conventionally identified as the $x z$ plane, corresponding to the central "meridian" in the figures. 
The electron density varies smoothly along the whole spherical surface of the quartet, while showing more pronounced peaks and valleys in the doublet. Maxima are seen in regions as far away as possible from the metal to ligand directions. This is expected, since it leads to a reduction of the repulsion between the $d$ orbitals of the metal and the $\sigma$ orbitals of the ligands. In the quartet the larger contribution to the non spherical electron charge distribution arises from the $d_{\mathrm{z}^{2}}$ and $d_{\mathrm{x}^{2}-\mathrm{y}^{2}}$ (both a') and $d_{\mathrm{xy}}$ (a") orbitals, with minor contributions from the remaining $d$ orbitals. The $d_{\mathrm{z}^{2}}$ orbital, pointing toward the centroid of the Cp ring, is singly occupied in both states, as it can be argued from the excess spin density in the polar region, upper part of Figure 2, and by the substantially equivalent electron densities of the ${ }^{2} \mathrm{~A}^{\prime}$ and ${ }^{4} \mathrm{~A} "$ states in the same region, which is where the $d_{\mathrm{z}}$ orbital exhibits an angular maximum. On the contrary, remarkable differences appear in the equatorial region, where the $d_{\mathrm{x}^{2}}-\mathrm{y}^{2}$ orbital is doubly occupied in the doublet state and singly occupied in the quartet. The region roughly located between the $\mathrm{Cl}$ atoms (left or right lower end of the south "tropics") shows a greater charge density in the quartet than in the doublet state. This is the region which hosts the empty $d$ orbital that will accommodate the lone pair of the incoming phosphorus atom in the $\mathrm{PH}_{3}$ addition. Finally, the quartet densities in the two figures shows a similar pattern, their difference corresponding to the (constant) spherical contribution to the electron charge density at the given radial distance from the metal. All the non spherical contribution comes apparently from the unpaired $d$ electrons.

In Figure 3 both the total and excess spin density of the 15-electron $\mathrm{CpCr}\left(\mathrm{CH}_{3}\right)\left(\mathrm{PH}_{3}\right)$ ${ }^{2} \mathrm{~A}$ " state resulting from the Kohn-Sham orbitals of the V-BLYP calculation are displayed. The total spin density has an angular behavior similar to that of the $\mathrm{CpCrCl}_{2}\left(\mathrm{PH}_{3}\right)$ 15-electron ${ }^{4} \mathrm{~A}$ " state, cf. bottom section of Figure 1. This is consistent with the three electrons in three different orbitals picture discussed above. A striking confirmation comes from the excess spin density map on the bottom part of Figure 3. Negative densities appear in two nearly equatorial lobes, the absolute value being maximum on the $x z$ plane. Apart from the sign, this maximum resembles that of the ${ }^{4} \mathrm{~A} "$ 15-electron $\mathrm{CpCrCl}_{2}\left(\mathrm{PH}_{3}\right)$ complex, cf. Figure 2. Going into some 
detail, the $\beta$ orbital is a mixing of $d_{\mathrm{z}^{2}}, d_{\mathrm{x}^{2}-\mathrm{y}^{2}}$ and $d_{\mathrm{xz}}$ orbitals, and it has an a' symmetry. The other two half-filled orbitals are of a" symmetry and essentially of $d_{\mathrm{z}^{2}}$ (with $d_{\mathrm{xz}}$ contributions) and $d_{\mathrm{xz}}\left(\right.$ partly $\left.d_{\mathrm{yz}}\right)$ character.

The electronic structure of the corresponding spin doublet 17-electron $\mathrm{CpMX}_{2}\left(\mathrm{PH}_{3}\right)_{2}$ complexes corresponds to that previously described by Hoffmann. ${ }^{31}$ There are only two valence-shell metal-based orbitals available for the three metal electrons, these being essentially pure equatorial (1a") and nearly pure polar $d_{z^{2}}$ (1a') pointing toward the barycenter of the $\mathrm{Cp}$ ring, conventionally located on the $z$ axis. A quartet state for this system would require occupation of an orbital with metal-ligand antibonding character, resulting in the expectation of a much higher energy. For this reason, this system has only been calculated in the more reasonable (and experimentally verified) doublet state which corresponds to the orbital occupation $\left(1 \mathrm{a}^{\prime \prime}\right)^{2}\left(1 \mathrm{a}^{\prime}\right)^{1}$.

B. Comparison between computational approaches. The systems under study, involving nearly degenerate $d$ orbitals and the determination of doublet to quartet energy splittings, are evidently not suitable for an Hartree-Fock approximation. SCF gives in this case much larger energy gaps, longer bond distances and inadequate estimates of the bond angles. Thus, even if the qualitative picture is well outlined in the independent particle approximation, a good account of electron correlation is needed in order to get into a satisfactory quantitative agreement with experiment, at least as far as structural parameters are concerned. Also, electron correlation, being more effective in the doublet state than in the quartet, has the sizable effect of reducing the energy gap between the lower quartet state and the upper doublet state in all 15-electron systems studied here, thus lowering noticeably the size of the doublet to quartet splitting. As a striking example, calculations performed with the LanL2DZ basis on the $\mathrm{CpCrCl}_{2}\left(\mathrm{PH}_{3}\right)$ 15-electron systems lead to a quartet-doublet energy splitting being reduced from about $62.6 \mathrm{kcal} / \mathrm{mole}(\mathrm{SCF})$ to about $43.3 \mathrm{kcal} / \mathrm{mole}$ upon introduction of some correlation (MP2). 
B.1. Bond distances and bond angles and comparison with experiment. For those systems having an experimentally determined related structure, i.e. ${ }^{4} \mathrm{~A} " \mathrm{CpCrCl}_{2}\left(\mathrm{PH}_{3}\right)$ and ${ }^{2} \mathrm{~A}^{\prime} \mathrm{CpMoCl}_{2}\left(\mathrm{PH}_{3}\right)_{2}$, the effect of the different basis sets and approaches on the relevant bond distances within the coordination sphere of the metal and on the bond angles involving the metal center and the ligands is schematically illustrated in Figures 4 and 5. A comparison with the available experimental values is made. Figure 6 shows the behavior of the relevant bond distances and that of the bond angles within the $\mathrm{Cr}$ coordination sphere for the five calculations performed here on the system ${ }^{4} \mathrm{~A} " \mathrm{CpCr}\left(\mathrm{CH}_{3}\right)_{2}\left(\mathrm{PH}_{3}\right)$ system. A comparison with the experimental structural parameters of the related $\mathrm{Cp} * \mathrm{Cr}\left(\mathrm{CH}_{3}\right)_{2}\left(\mathrm{PMe}_{3}\right)$ complex is included.
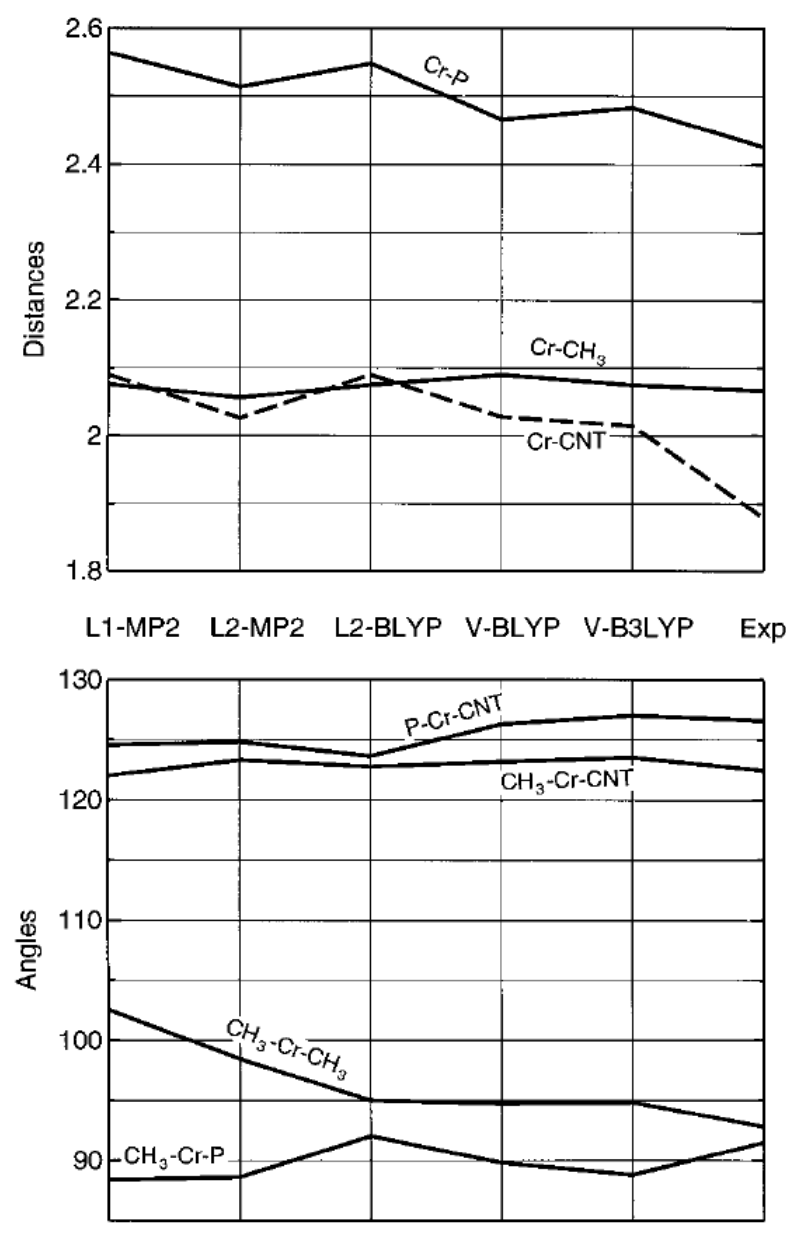
Figure 6 Optimized distances (in $\AA$ ) and bond angles (in degrees) for the eclipsed (III) ${ }^{4}$ A" $\mathrm{CpCr}\left(\mathrm{CH}_{3}\right)_{2}\left(\mathrm{PH}_{3}\right)$ system and comparison with the experiment $\left(\mathrm{Cp}^{*} \mathrm{Cr}\left(\mathrm{CH}_{3}\right)_{2}\left(\mathrm{PMe}_{3}\right)\right.$, Ref. 2). CNT is the centroid of the ring.

All optimized distances related to the metal coordination sphere for the reference states are slightly longer than the experimental values (cf. Tables and Figures 4, 5 ad 6). In most cases the difference between our V-BLYP or V-B3LYP distances and experiment is within a few hundredth of an $\AA$. The calculated angular parameters are in general within $3^{\circ}-4^{\circ}$ from experiment.

For the $\mathrm{CpCrCl}_{2}\left(\mathrm{PH}_{3}\right){ }^{4} \mathrm{~A}$ " 15-electron system, a convergence pattern towards the experimental reference is discernible in the study of the bond distances (Figure 4), moving from a smaller basis set (L1-MP2) through LanL2DZ (L2-MP2 and L2-BLYP) to the largest set (V-BLYP and V-B3LYP). The behavior is smooth, and variations are minor, for the bond angles. If anything, V-BLYP - and even more V-B3LYP - appear to go in the wrong direction with respect to the other three approximations, for the P-Cr-CNT $(\mathrm{CNT}=$ centroid of the $\mathrm{Cp}$ ring) and $\mathrm{Cl}-\mathrm{Cr}-\mathrm{P}$ angles. In this case, however, a close inspection of the experimental structure reveals potential steric interactions between the uncoordinated arm of the monodentate dmpm ligand and the chlorine atoms. These interactions could be responsible for artificially increasing the experimental Cl-Cr-P angles and decreasing the CNT-Cr-P angle. In fact, the phosphine ligand is less covalently $\sigma$-bound to the metal center than $\mathrm{Cl}$, thus the angular parameters related to $\mathrm{P}$ are predicted to be more susceptible to steric distortions than those related to $\mathrm{Cl}^{32}$ 

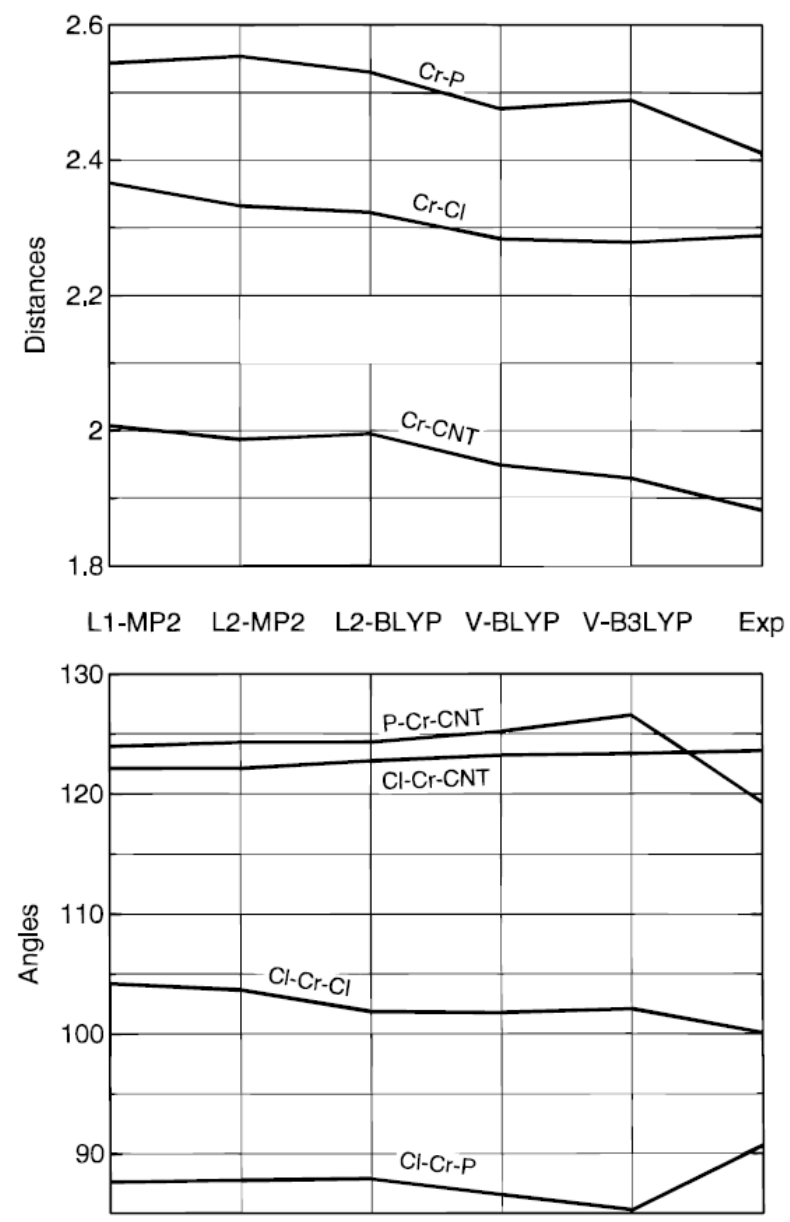

Figure 4 Optimized distances (in $\AA$ ) an d bond angles (in degrees) for the eclipsed (III) ${ }^{4} \mathrm{~A}$ " $\mathrm{CpCrCl}_{2}\left(\mathrm{PH}_{3}\right)$ system and comparison with the experiment $\left(\mathrm{CpCrCl}_{2}(\mathrm{dmpm})\right.$, Ref.4). CNT is the centroid of the Cp ring.

The corresponding ${ }^{4} \mathrm{~A}$ " dimethyl system, $\mathrm{CpCr}\left(\mathrm{CH}_{3}\right)_{2}\left(\mathrm{PH}_{3}\right)$ seems to be more suitable for MP2 than for DFT (Figure 6), once again relative to the experimental reference. In this case L2-MP2 furnishes consistently shorter distances than L2-BLYP, which leads us to predict that a V-MP2 geometry optimization, if attempted, might be able to reduce the remaining gap between experiment and computation. The large gap between calculated and experimental CrCNT parameter may in part be due to the use of the $\mathrm{Cp}$ model for the $\mathrm{Cp}$ * ligand. The latter is electronically a stronger donor with more expanded orbitals and a shorter $\mathrm{Cr}-\mathrm{Cp}$ * distance may thus be the result of better $\mathrm{Cr}-\mathrm{Cp}^{*}$ overlap. Concerning the bond angles for this 
compound, the agreement is once again quite good, with the more sophisticated V-BLYP and V-B3LYP providing better agreement for the $\mathrm{P}-\mathrm{Cr}-\mathrm{CNT}$ angle, while the Me-Cr-P angle is better reproduced by the L2-BLYP.

The LanL1DZ basis performs distinctly worse than the larger sets for the Cr complexes while, surprisingly, L1-MP2 appears to be closer than the more "expensive" approaches for some structural parameters in the ${ }^{2} \mathrm{~A}^{\prime} \mathrm{CpMoCl}_{2}\left(\mathrm{PH}_{3}\right)_{2}$ complex. This is particularly true for the Mo-CNT distance and for most of the bond angles (Figure 5). It seems also that MP2 is on the average more adequate than DFT to reproduce the structural parameters of this Mo system. It is to be borne in mind that the experiment always refers to systems with alkyl substituted ligands. Thus, the steric and electronic effects of these substituents on the overall structure, for instance the ability to modify the $\pi$-donor characteristics of the $\mathrm{Cp}$ ligand or the $\sigma$-donor/ $\pi$-acceptor characteristics of the phosphine ligand, may be non negligible. Indeed, the use of $\mathrm{PH}_{3}$ as a model for alkyl-substituted ligands leads to too weak metal to ligand bond energies. $^{17}$ 

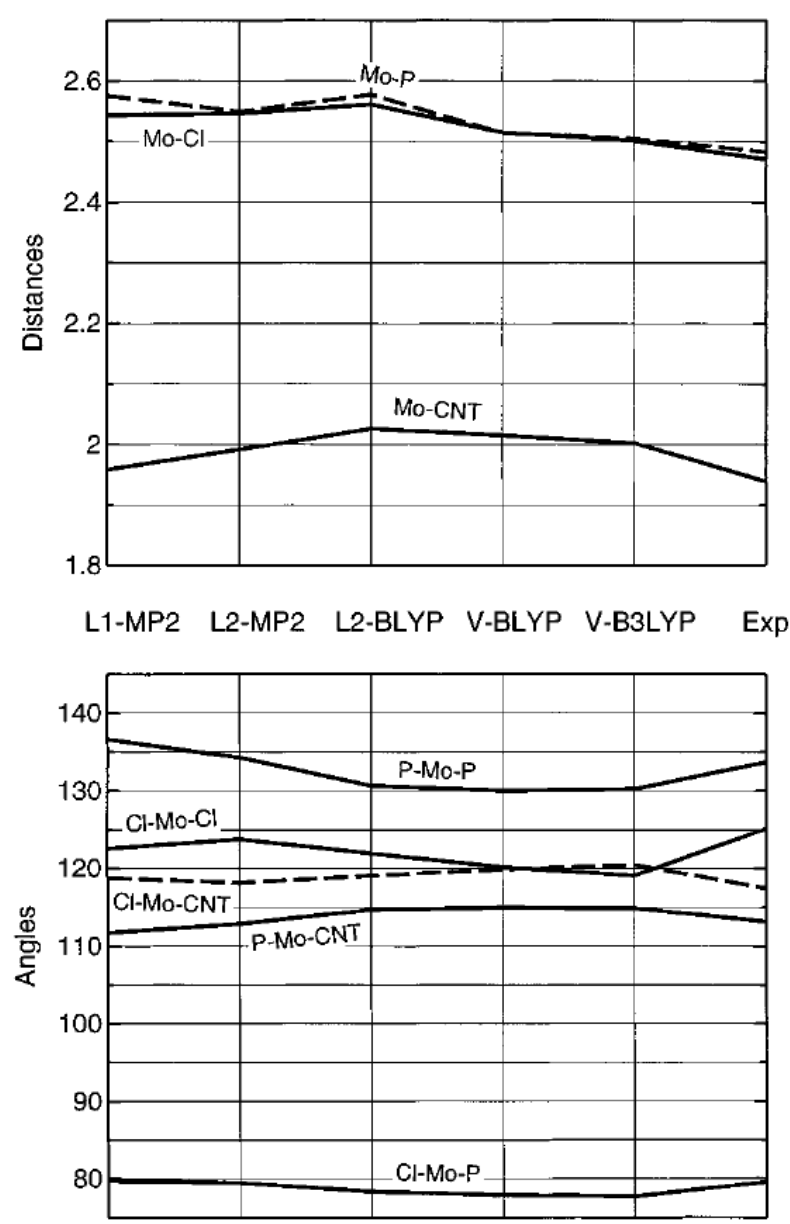

Figure 5 Optimized distances (in $\AA$ ) and bond angles (in degrees) for the ${ }^{2} \mathrm{~A}$ ' $\mathrm{CpMoCl}_{2}\left(\mathrm{PH}_{3}\right)_{2}$ system with symmetry-equivalent $\mathrm{PH}_{3}$ ligands (II) and comparison with the experiment $\left(\mathrm{CpMoCl}_{2}\left(\mathrm{PMe}_{3}\right)_{2}\right.$, Ref. $\left.3 b\right)$. CNT is the centroid of the $\mathrm{Cp}$ ring.

Stable $\mathrm{CpCr}$ (III) complexes with a doublet state configuration, either with a 15 or 17 electron configuration, and stable 15-electron $\mathrm{CpMo}$ (III) complexes, either with a doublet or quartet ground state, do not exist. The configurations optimized for $\mathrm{CpCrX} 2\left(\mathrm{PH}_{3}\right)_{2}$ and for ${ }^{4} \mathrm{~A}$ " $\mathrm{CpMoCl}_{2}\left(\mathrm{PH}_{3}\right)$ are quite similar to those of the known $\mathrm{CpMoCl} 2\left(\mathrm{PR}_{3}\right)_{2}$ and $\mathrm{CpCrX} 2\left(\mathrm{PR}_{3}\right)$ compounds, respectively.

It is interesting to analyze the structural changes associated with the spin change from the ground state ${ }^{4} \mathrm{~A}$ " to the excited state ${ }^{2} \mathrm{~A}$ ' in the chlorine systems. Reference will be made 
here to the V-BLYP optimized parameters. V-B3LYP behaves essentially in the same way for the $\mathrm{Cr}$ (III) system, while variations are less pronounced than in V-BLYP for the Mo(III) complex. The angle Cl-M-P decreases slightly $\left(86.53^{\circ}\right.$ vs. $86.46^{\circ}$ in $\mathrm{CpCrCl}_{2}\left(\mathrm{PH}_{3}\right)$ and $86.05^{\circ}$ vs. $83.23^{\circ}$ in $\left.\mathrm{CpMoCl}_{2}\left(\mathrm{PH}_{3}\right)\right)$, whereas the $\mathrm{Cl}-\mathrm{M}-\mathrm{Cl}$ angle increases $\left(101.78^{\circ}\right.$ vs. $105.12^{\circ}$ in $\mathrm{CpCrCl}_{2}\left(\mathrm{PH}_{3}\right)$ and $97.60^{\circ}$ vs. $123.80^{\circ}$ in $\left.\mathrm{CpMoCl}_{2}\left(\mathrm{PH}_{3}\right)\right)$. Also, the M-P, M-CNT and M-Cl distances decrease. Thus the $\mathrm{Cl}$ ligands slightly move toward the $\mathrm{PH}_{3}$ ligand. This change corresponds to a rearrangement of the three ligands from a three-legged piano stool toward a four-legged piano stool with a missing leg. In other words, space is made up for binding of an extra ligand in the proper position to lead to the formation of a four-legged piano stool 17electron geometry. The process, which is particularly evident in the Mo(III) system, is schematically shown in an exaggerated form in Scheme 1.

Scheme 1:
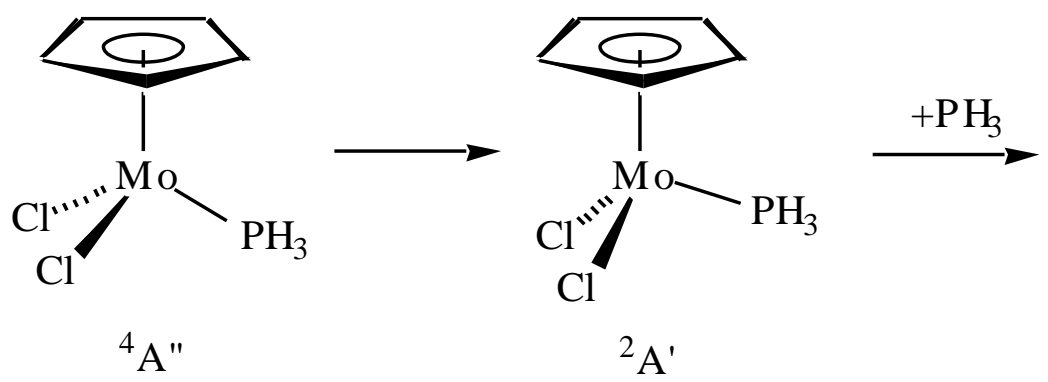

${ }^{2} \mathrm{~A}^{\prime}$

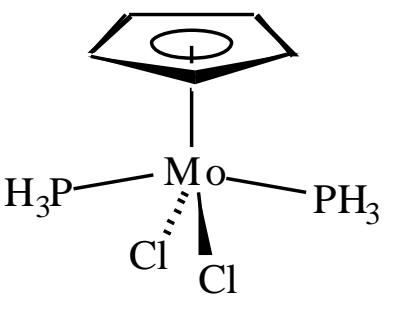

${ }^{2} \mathrm{~A}^{\prime}$

It is also of some interest to compare the structures of the 15-electron and 17-electron dichloride complexes of $\mathrm{Cr}$ (III) and $\mathrm{Mo}(\mathrm{III})$ (Tables 1 and 2). As expected, metal-ligand distances are larger $(0.1 \AA$ on the average) for the Mo(III) complexes in view of its greater atomic radius. Note also that bond distances are consistently larger in the 15-electron quartet states with respect to the corresponding 15-electron doublet states. An inspection of Figures 1 and 2 suggests a possible explanation: the "valleys" of the charge distribution of the 15electron doublet state allow a closer approach of the incoming ligand with respect to that permitted in the 15-electron quartet. In other words, the greater angular flexibility of the 
doublet allows a better penetration of metal electron density by the ligands, with minor repulsion energy between the $d$ orbitals and the $\sigma$ electrons of the ligand.

As far as bond angles are concerned, while the Cl-M-P angles have in general little dependence on the nature of the metal in both 15- and 17-electron structures, the remaining relevant angles show remarkable differences, strongly influenced also by the form of the Exchange functional employed (B or B3). This strong unexpected dependence on the form of the Exchange functional is related to the noticeable structural differences observed between the ${ }^{2} \mathrm{~A}^{\prime}$ states of the $\mathrm{CpMoCl}_{2}\left(\mathrm{PH}_{3}\right)$ complex in the V-BLYP and V-B3LYP calculations, see below. Thus in the V-BLYP calculation the Cl-M-Cl angle of the ${ }^{2} \mathrm{~A}$ ' 15-electron systems goes from $105.12^{\circ}$ for $\mathrm{M}=\mathrm{Cr}$ to $123.80^{\circ}$ for $\mathrm{M}=\mathrm{Mo}$; the CNT-M-P in the same structure goes from $116.64^{\circ}$ for $\mathrm{M}=\mathrm{Cr}$ to $134.90^{\circ}$ for $\mathrm{M}=\mathrm{Mo}$ and $\mathrm{CNT}-\mathrm{M}-\mathrm{Cl}$ goes from $124.63^{\circ}$ for $\mathrm{M}=\mathrm{Cr}$ to $113.97^{\circ}$ for $\mathrm{M}=\mathrm{Mo}$. V-B3LYP furnishes instead angles quite similar for the ${ }^{2} \mathrm{~A}^{\prime}$ 15-electron systems of $\mathrm{Cr}(\mathrm{III})$ and $\mathrm{Mo}(\mathrm{III})$ : Cl-M-Cl (106.20 $0^{\circ}$ vs. $\left.110.25^{\circ}\right)$, CNT-M-P $\left(117.58^{\circ}\right.$ vs. $\left.117.87^{\circ}\right)$ and $\mathrm{CNT}-\mathrm{M}-\mathrm{Cl}\left(124.44^{\circ}\right.$ vs. $\left.122.54^{\circ}\right)$. It is also remarkable that while the 15-electron doublet and quartet structures of the $\mathrm{CpCrCl}_{2}\left(\mathrm{PH}_{3}\right)$ system are substantially similar - independent of the computational approximation - large bond angle rearrangements occur upon pairing the electrons in the $\mathrm{CpMoCl}_{2}\left(\mathrm{PH}_{3}\right)$ 15-electron systems in the V-BLYP calculation: for instance, the $\mathrm{Cl}-\mathrm{Mo}-\mathrm{Cl}$ angle goes from $123.80^{\circ}$ to $97.60^{\circ}$, the $\mathrm{CNT}-\mathrm{M}-\mathrm{Cl}$ from $113.97^{\circ}$ to $123.92^{\circ}$ and the CNT-M-P from $134.90^{\circ}$ to $128.09^{\circ}$. Variations are less dramatic using B3LYP: the Cl-Mo-Cl angle goes from $110.25^{\circ}$ to $97.85^{\circ}$, the $\mathrm{CNT}-\mathrm{M}-\mathrm{Cl}$ from $122.54^{\circ}$ to $124.13^{\circ}$ and the CNT-M-P from $117.87^{\circ}$ to $129.80^{\circ}$.

Another general interesting trend can be observed by examining how the metal to ligand distances vary when moving from the 15 -electron ${ }^{4} \mathrm{~A}$ " species to the corresponding ${ }^{2} \mathrm{~A}$ ' 17-electron complexes. Upon addition of the phosphine ligand, the M-X distance increases (0.11 $\AA$ on the average), the M-P and M-Cp distances decrease (0.06 $\AA$ in the chlorine complexes, $0.11 \AA$ in the methyl complexes) for all three systems under study here $\mathrm{CpCrCl}_{2}\left(\mathrm{PH}_{3}\right), \mathrm{CpMoCl}_{2}\left(\mathrm{PH}_{3}\right)$ and $\mathrm{CpCr}\left(\mathrm{CH}_{3}\right)_{2}\left(\mathrm{PH}_{3}\right)$. It looks like upon the addition of a 
second phosphine ligand, the chlorine or methyl ligand are pushed away, while both the Cp ring and the phosphines get closer to the metal center. This shows a greater "affinity" of the metal in its higher saturation state for the cyclopentadienyl and phosphine than for the chlorine and methyl ligands.

B.2. Energies and comparison with experiment. Table 4 shows the changes occurring in the relative energies, i.e. quartet to doublet splittings in the 15-electron complexes and the energy difference between reactants and products in the reaction $\mathrm{CpMX}_{2}\left(\mathrm{PH}_{3}\right)\left({ }^{4} \mathrm{~A}^{\prime \prime}\right)$ $+\mathrm{PH}_{3} \rightleftarrows \mathrm{CpMX}_{2}\left(\mathrm{PH}_{3}\right)_{2}\left({ }^{2} \mathrm{~A}^{\prime}\right)$ for the three systems studied here $(\mathrm{M}=\mathrm{Cr}, \mathrm{X}=\mathrm{Cl} ; \mathrm{M}=$ Mo, $\mathrm{X}=\mathrm{Cl}$ and $\mathrm{M}=\mathrm{Cr}, \mathrm{X}=\mathrm{CH}_{3}$ ) as the sophistication of the ab-initio approach increases. We stress that no effort was made to determine reaction paths and transition states for the above reactions.

For all three reactions the energy of the 15 -electron ${ }^{4} \mathrm{~A} "$ state is used as a reference. As said above, generally the 15-electron doublet ground state has A' symmetry. The $\mathrm{CpCr}\left(\mathrm{CH}_{3}\right)_{2}\left(\mathrm{PH}_{3}\right)$ system is an exception when employing a DFT approach: the ground state has A" symmetry. The $\mathrm{M}-\mathrm{PH}_{3}$ bond formation energy along the spin doublet surface is larger for Mo than for Cr, in line with the generally accepted view that bond strengths increase upon descending a group of transition metals. ${ }^{5}$ An incorrect interpretation of the computational data in our preliminary communication ${ }^{10}$ led to the reporting of an erroneous $\mathrm{Cr}-\mathrm{PH}_{3}$ bond energy for the $\mathrm{Cr}(\mathrm{III})-\mathrm{Chloride}$ system in the L2-BLYP approximation. 
Table 4. Relative energies (in kcal/mole) of geometry optimized $\mathrm{CpMX}_{2}\left(\mathrm{PH}_{3}\right)+\mathrm{PH}_{3}$ vs. $\mathrm{CpMX}_{2}\left(\mathrm{PH}_{3}\right)$ systems. $^{a}$

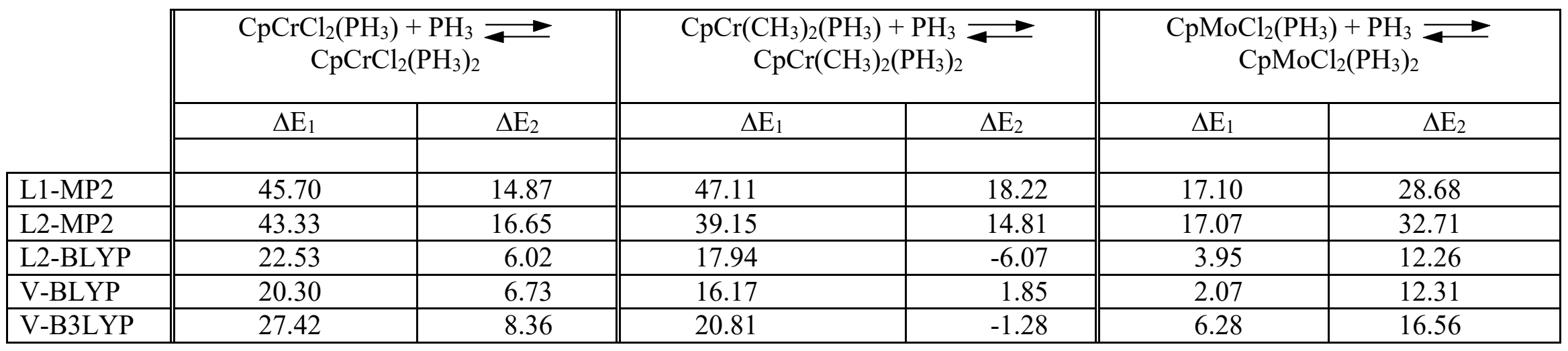

${ }^{a}$ Quartet to doublet splittings in the 15 -electron systems $-\Delta \mathrm{E}_{1}=\mathrm{E}(\mathrm{S}=1 / 2 ; 15$-el. $)$ - $\mathrm{E}(\mathrm{S}=3 / 2 ; 15$-el. $)$ - and $\mathrm{M}-\mathrm{PH}_{3}$ bond formation energy along the spin doublet surface $-\Delta \mathrm{E}_{2}=\mathrm{E}(\mathrm{S}=1 / 2 ; 15$-el. $)+\mathrm{E}\left(\mathrm{PH}_{3}\right)-\mathrm{E}(\mathrm{S}=1 / 2 ; 17$-el. $)$. The 15-electron quartet states have always ${ }^{4} \mathrm{~A}^{\prime}$ symmetry; the 15-electron doublet states have ${ }^{2} \mathrm{~A}^{\prime}$ symmetry except for the three DFT calculations of the $\mathrm{CpCr}_{2}\left(\mathrm{CH}_{3}\right)_{2}\left(\mathrm{PH}_{3}\right)+\mathrm{PH}_{3}$ $\mathrm{CpCr}\left(\mathrm{CH}_{3}\right)_{2}\left(\mathrm{PH}_{3}\right)_{2}$ system, where the symmetry is ${ }^{2} \mathrm{~A}$ "; the 17 -electron doublet states have always ${ }^{2} \mathrm{~A}^{\prime}$ symmetry. 
A common feature to all three reactions is the much larger (closer to those given by SCF) energy gaps provided by the MP2 relative to the DFT calculations. The quartet to doublet splittings for the 15-electron systems follow a common pattern in all three cases, with L1-MP2 > L2-MP2 >> V-B3LYP > L2-BLYP > V-BLYP. Also the energy differences between the 15 -electron ${ }^{2} \mathrm{~A}$ ' systems plus $\mathrm{PH}_{3}$ at infinite distance and 17-electron adducts is in all cases much larger with MP2 than with DFT. DFT absolute energies are much lower than MP2 absolute energies, indicating apparently a greater ability of DFT to recover electron correlation. This increased ability of DFT becomes more evident in the stabilization of the doublet (more electron-correlated) rather than the quartet states, and leads to a generalized lowering of the energy gaps.

The case of the $\mathrm{Cr}(\mathrm{III})-\left(\mathrm{CH}_{3}\right)$ systems deserves a brief comment. A negative estimate of the $\mathrm{Cr}(\mathrm{III})-\mathrm{PH}_{3}$ bond energy in the dimethyl complex is found in the L2-BLYP and VB3LYP calculations, while V-BLYP furnishes a somehow surprisingly small positive value. It is evident, in view of the discussion in the preceding sections, that the 15 -electron ${ }^{2} \mathrm{~A}$ " state does not correlate to the ${ }^{2} \mathrm{~A}$ ' 17-electron state, the order of the doublet states being reversed as the phosphine approaches from infinity to bond distance. These gaps for the addition of the phosphine along the spin doublet surface in the DFT calculations on the Cr(III)-methyl complexes cannot thus be taken as estimates of the new bond formation energy.

Neither for $\mathrm{M}=\mathrm{Cr}$ nor for $\mathrm{M}=\mathrm{Mo}$ are experimental measurements of quartet-doublet gaps for the 15-electron systems or $\mathrm{M}-\mathrm{PH}_{3}$ bond dissociation energies for the 17-electron systems available. It is however known that the Cr systems always adopt a spin quartet 15electron configuration and that the Mo(III) systems are stable instead with a 17-electron spin doublet configuration. The results of our calculations are thus in qualitative agreement with these experimental observations at all levels of theory.

In conclusion, both MP2 and DFT approaches afford results in agreement with the stability trends and provide essentially equally suitable optimized geometries. The fact that 
DFT is computationally less demanding than MP2 becomes the only discriminating factor justifying the adoption of DFT for our largest calculations.

B.3. BLYP vs. B3LYP. Since B3LYP differs from BLYP for the inclusion of a fraction of the exact HF exchange, ${ }^{25}$ it could in principle be expected to perform better than its predecessor. On the other hand, given that the B3 exchange potential is obtained by fitting a series of experimental data that does not include systems with transition metals, there is in principle no guarantee that it is more accurate than the 1988 Becke exchange functional in our case.

B3LYP gives sensibly lower absolute energies with respect to BLYP. The energy lowering is more effective for the 15 -electron quartet states. This leads to an increase in the doublet to quartet splittings of about $7.1 \mathrm{kcal} / \mathrm{mole}, 4.6 \mathrm{kcal} / \mathrm{mole}$ and $4.3 \mathrm{kcal} / \mathrm{mole}$ for the $\mathrm{Cr}(\mathrm{III})-\mathrm{Cl}, \mathrm{Cr}(\mathrm{III})-\mathrm{Me}$ and $\mathrm{Mo}(\mathrm{III})-\mathrm{Cl}$ complexes, respectively. With B3LYP the energy gain of the high-spin 15-electron state for the $\mathrm{Cr}$ (III) systems is also larger than that observed for the corresponding 17-electron species: the gap increases by $5.5 \mathrm{kcal} / \mathrm{mole}$ and $7.8 \mathrm{kcal} / \mathrm{mole}$ for $\mathrm{Cr}(\mathrm{III})-\mathrm{Cl}$ and $\mathrm{Cr}(\mathrm{III})-\mathrm{CH}_{3}$, respectively. B3LYP thus apparently shows a preference for high-spin systems, where the Exchange is expected to give a larger contribution to the total energy. For the $\mathrm{Mo}(\mathrm{III})-\mathrm{Cl}$ complexes, on the contrary, a compensation between several terms in the effective Hamiltonian yields in B3LYP a reaction energy very close to that calculated in the BLYP approximation.

If the effects on the relative energies are quite significant, the overall effect on the geometry is instead negligible. Metal to ligand distances very rarely change by more than 0.01-0.02 A. Angles change by $1^{\circ}-2^{\circ}$ on the average. The 15 -electron lowest ${ }^{2} \mathrm{~A}^{\prime}$ state of $\mathrm{CpMoCl}_{2}\left(\mathrm{PH}_{3}\right)$ is in this sense an exception, since - as mentioned above - it shows surprisingly large rearrangements of the angles passing from BLYP to B3LYP in basis V: Cl-Mo-Cl decreases from $123.80^{\circ}$ to $110.25^{\circ}, \mathrm{CNT}-\mathrm{Mo}-\mathrm{Cl}$ increases from $113.97^{\circ}$ to $122.54^{\circ}$ and $\mathrm{CNT}$ Mo-P decreases from $134.90^{\circ}$ to $117.87^{\circ}$. The $\mathrm{Cp}$ plane also rearranges sensibly. 
All in all, the choice of BLYP or B3LYP leads to effects on the electronic structure and on the geometries of the complexes studied here that do not influence the overall conclusions of our study.

B.4. Effect of the cyclopentadienyl ring conformation. As mentioned in the Computational details section, the effect of the rotational conformation of the $\mathrm{Cp}$ ring has been investigated for most systems. In agreement with experimental evidence, ${ }^{27}$ the effect of rotation appears to be negligible in most cases. For instance, the 15-electron quartet state in both $\mathrm{Cl}$ and $\mathrm{CH}_{3}$ complexes of $\mathrm{Cr}(\mathrm{III})$, as well as the 17-electron doublet state of the $\mathrm{CpMoCl}_{2}\left(\mathrm{PH}_{3}\right)_{2}$ system, exhibit at most a few hundredth of a $\mathrm{kcal} / \mathrm{mole}$ difference in energy in the two possible symmetric conformations (I and II for the 17-electron complexes, III and IV for the 15-electron complexes) at all computational levels.

The rotation of the ring has a somewhat larger effect on higher lying ${ }^{2} \mathrm{~A}$ ' states for the 15-electron complexes. The "staggered" $\mathrm{CpMX}_{2}\left(\mathrm{PH}_{3}\right)(\mathbf{I V})$ is higher in energy relative to the "eclipsed" (III) conformer (ca. $3 \mathrm{kcal} / \mathrm{mole}$ for $\mathrm{M}=\mathrm{Cr}, \mathrm{X}=\mathrm{CH}_{3}$; ca. $0.8 \mathrm{kcal} / \mathrm{mole}$ for $\mathrm{M}=$ Mo, $\mathrm{X}=\mathrm{Cl}$ at the V-BLYP level). Geometries are also noticeably different. The "staggered" (IV) doublets display longer bond distances and quite different bond angles (for instance: $117.09^{\circ}$ vs. $134.90^{\circ}$ for P-Mo-CNT; $122.71^{\circ}$ vs. $113.97^{\circ}$ for Cl-Mo-CNT; $108.62^{\circ}$ vs. $123.80^{\circ}$ for Cl-Mo-Cl) relative to the "eclipsed" (III) conformers. It is not straightforward to find the causes of these large rearrangements: an interplay of steric and electronic factors which is far from being obvious.

C. Role of the spin pairing and of the metal to $\mathrm{PH}_{3}$ bond formation energy. One of the goals of these theoretical calculations was to establish what is responsible, on one side, for the lack of binding of a 2-electron donor $\mathrm{L}$ ligand (modeled by $\mathrm{PH}_{3}$ ) to a 15-electron $\mathrm{CpCrX}_{2} \mathrm{~L}$ system and, on the other side, for the lack of ligand dissociation from a stable 17electron $\mathrm{CpMoX}_{2} \mathrm{~L}_{2}$ system. We can ideally break up the process of ligand addition to the 15electron quartet complex into two steps, i.e. a spin pairing to prepare the excited doublet state, followed by $\mathrm{PH}_{3}$ coordination along the spin doublet surface. The energy involved in this 
"coordination step" can be viewed as a representative $\mathrm{Cr}(\mathrm{III})-\mathrm{PH}_{3}$ or $\mathrm{Mo}(\mathrm{III})-\mathrm{PH}_{3}$ binding energy. The binding of the incoming $\mathrm{PH}_{3}$ gives a stabilization which may thus be largely ascribed to the formation of a new metal to phosphorus bond along the doublet surface.

Even within the limitations of the theoretical models, it appears that the binding energies in the $\mathrm{Cr}$ dichloride and dimethyl systems are too small to compensate for the "pairing energy" discussed above, and contribute to maintain an energetic preference for the 15electron quartet system. For the Mo dichloride systems, on the other hand, the doublet to quartet splitting in the 15 -electron system is much smaller relative to the Cr systems, while the "dissociation energy" of the $\mathrm{Mo}^{-\mathrm{PH}_{3}}$ bond along the spin doublet surface is larger as expected. ${ }^{5}$ As discussed above, the factors influencing the size of the gap between 15-electron and 17-electron doublet states are numerous. In this respect, useful hints come from Figure 7, which displays the overlap of the $\mathrm{M} d$ and $\mathrm{P} p$ orbitals involved in the M-P bond in the $\mathrm{CpMCl}_{2} \mathrm{PH}_{3}$ 15-electron ${ }^{4} \mathrm{~A} "$ system $(\mathrm{M}=\mathrm{Cr}, \mathrm{Mo})$.

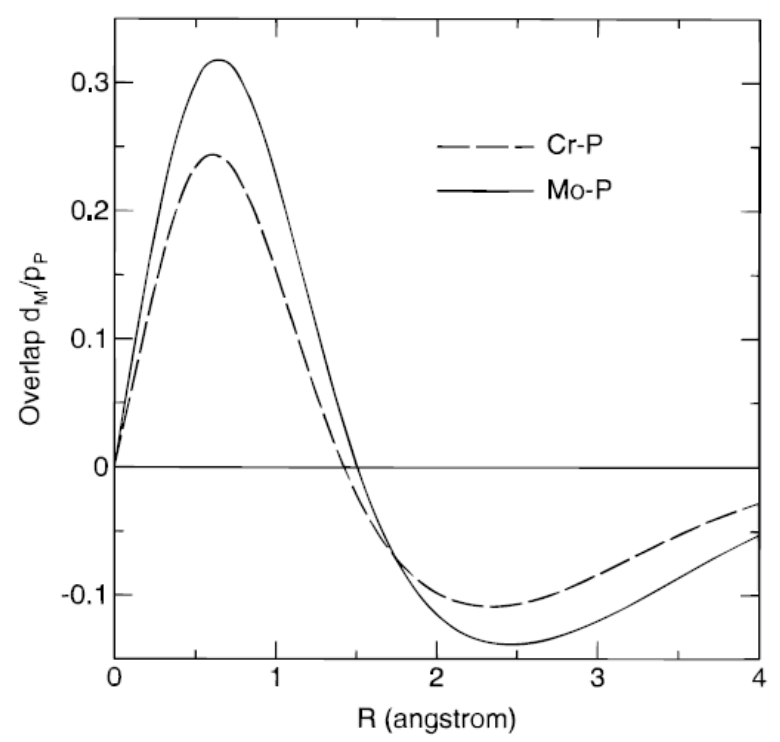

Figure 7 Overlap between the $\mathrm{n} d_{\mathrm{x}^{2}-\mathrm{y}^{2}}(\mathrm{n}=3$ for $\mathrm{M}=\mathrm{Cr}, \mathrm{n}=4$ for $\mathrm{M}=\mathrm{Mo})$ and the $3 p$ orbital of phosphorus along the M-P axis for the $\mathrm{CpMCl}_{2} \mathrm{PH}_{3}{ }^{4} \mathrm{~A}$ ” system. ROSCF calculations on basis LanL2DZ. 
Although obtained using ROSCF orbitals and basis LanL2DZ, the plot gives a good qualitative picture of the greater strength of the Mo-P bond, the overlap being larger than for the Cr-P bond. Note also that the minima of the two curves fall around $2.4 \AA$, very close to the estimates of the metal to phosphorus distance in Table 1. Apparently the maximum overlap criterion is respected for the metal-phosphine bond.

The results of our theoretical studies confirm the hypothesis that the spin state change has an important energetic effect in these systems. In simple words, the incoming ligand needs an empty metal-based orbital, which can only be made available by pairing two electrons in the quartet state and reaching the excited doublet state. Since the electrons must be paired in a relatively small $3 d$ orbital for $\mathrm{Cr}^{3+}$, the Coulomb and Exchange integrals are quite substantial. For $\mathrm{Mo}^{3+}$, on the other hand, the cost of pairing the electrons in a more diffuse $4 d$ orbital is expected to be much less. An analysis of the results following the method of Hall ${ }^{33}$ was made for the dichloride complexes of $\mathrm{Cr}$ and Mo. ${ }^{10}$ With this technique the unpaired orbitals of the higher spin state are used to describe the lower spin states, and to compute their energies. Although relaxation effects in the lower spin states are thus completely neglected, a quite satisfactory qualitative description of the main effects may still be achieved. The energy of the doublet was estimated using the Restricted Open-Shell SCF orbitals of the quartet state, and an approximate quartet-doublet gap was obtained in terms of appropriate orbital energies and Coulomb and Exchange integrals involving the three metal based $d$ orbitals of interest. ${ }^{10}$ This led to ascribe the larger "pairing energy" of $\mathrm{Cr}^{3+}$ with respect to $\mathrm{Mo}^{3+}$ to larger Coulomb and Exchange integrals, which in turn is a consequence of the greater radial contraction of the $d$ orbitals in the lighter metal. The Coulomb integrals, obtained by selecting the unpaired orbitals used to express the V-BLYP density with the method outlined in the Appendix, are on the average of $385 \mathrm{kcal} / \mathrm{mole}$ and $287 \mathrm{kcal} / \mathrm{mole}$ for the 15 -electron quartets of $\mathrm{Cr}(\mathrm{III})-\mathrm{Cl}$ and $\mathrm{Mo}(\mathrm{III})-\mathrm{Cl}$ systems, respectively. The same integrals, obtained in the LanL2DZ basis set and ROSCF approximation, had values of $517 \mathrm{kcal} / \mathrm{mole}$ and $345 \mathrm{kcal} / \mathrm{mole}$, respectively. ${ }^{10}$ 
One further point of interest in this study is the comparison between the chloride and methyl systems. It has been proposed by Hall et al. for various model systems of the known trans- $\mathrm{TiX}_{2}(\mathrm{dmpm})_{2}\left(\mathrm{X}=\mathrm{Cl}, \mathrm{CH}_{3}\right)$ compounds that differences in Coulomb and Exchange integrals are responsible for the observed difference in spin state between the two systems. ${ }^{33}$ Essentially, the less electronegative methyl groups allow the metal center to expand its orbitals to a greater extent with respect to the more electronegative chloride ligands, resulting in lower Coulomb and Exchange integrals and a greater stability of the lower spin state for the dimethyl compound. In the present study, we were anticipating a similar situation for the 15-electron $\mathrm{CpCrX} 2\left(\mathrm{PH}_{3}\right)$ system, resulting in a slightly smaller quartet-doublet gap for the dimethyl compound. However, the calculated gap is essentially the same for the two systems in MP2, the difference being around $3 \mathrm{kcal} / \mathrm{mole}$. We stress here that the comparison at the DFT level of approximation would be between doublet states corresponding to different configurations. An analysis of the excess-spin orbitals of the 15-electron quartet states in the V-BLYP approximation done with the technique described in the Appendix shows in fact a comparable spatial extent of the metal based $3 d$ orbitals, resulting in averaged Coulomb integrals $\mathrm{J}=385$ $\mathrm{kcal} / \mathrm{mole}$ and $\mathrm{J}=378 \mathrm{kcal} / \mathrm{mole}$ for the $\mathrm{Cl}$ and methyl systems respectively. These values, together with other energy parameters, ${ }^{10}$ lead to a prediction of the energy gaps roughly of the same order: $30 \mathrm{kcal} /$ mole vs. $31 \mathrm{kcal} / \mathrm{mole}$ for $\mathrm{Cl}$ and $\mathrm{CH}_{3}$ respectively. The effect of the electronic and nuclear rearrangement reduce considerably this frozen-orbital estimate.

\section{Conclusions}

The experimental evidence that half-sandwich $\mathrm{Cr}$ (III) complexes prefer to adopt a 15electron, spin quartet configuration while Mo(III) complexes prefer to reach a stable 17electron configuration has been investigated from the theoretical point of view. The hypothesis that the cost of pairing the electrons into the required spin doublet configuration exceeds the energetic gain of forming the new bond for the $\mathrm{Cr}$ (III) systems has been confirmed and a 
quantitative estimate of the pairing energies has been obtained. The stabilization of the more saturated configuration by $\mathrm{M}-\mathrm{PH}_{3}$ bonding does not appear to be important for the $\mathrm{Cr}$ systems, whereas the stabilization energy provided by the new bond for the $\mathrm{CpMoCl}_{2}\left(\mathrm{PH}_{3}\right)_{2}$ system largely overcomes the energy spent to pair the electrons in the quartet 15 -electron state. The computed relevant distances and angles in the model systems studied here compare quite well with their related experimental counterparts.

The current study has also allowed us to compare quite different computational methods (e.g. MP2 and density functional techniques) for systems of experimental relevance and which involve open-shell configurations of varying spin multiplicity. Neither at the geometry, nor at the energy levels, has one of the two methods proven distinctly superior to the other. This is also in part due to the unavailability of experimental data for immediate comparison with our "model" systems.

The energetic effect of a spin state change on the relative stability of different electronic configurations for the general class of open-shell organometallic compounds has long escaped a concerted rationalization effort. ${ }^{1}$ Since the experimental measurement of bond dissociation energies and spin-forbidden electronic transitions is generally difficult, computational methods can lead to substantial advances in this area. The application of the methods presented in this contribution to other problems in the general area of open-shell organometallic compound is expected to lead to the rationalization of much experimental information.

\section{Appendix.}

In a Restricted Open Shell Hartree-Fock (ROHF) calculation singly and doubly occupied orbitals obey to different one-electron equations, and are well "separated" and easily identifiable. In Unrestricted calculations instead (the so-called Pople-Nesbet equations ${ }^{34}$ ) this does not generally happen, especially in systems with nearly degenerate doubly occupied and 
singly occupied orbitals, and where the excess spin may be distributed among the spinorbitals. To separate at least approximately the singly occupied orbitals from the others, we used the following procedure. The number of excess spin electrons $\left(N_{\alpha}>N_{\beta}\right)$ in the atomic basis set may be written as

$$
N^{\alpha-\beta}=\operatorname{Tr}\left(\mathbf{S}^{1 / 2} \mathbf{P}^{\alpha-\beta} \mathbf{S}^{1 / 2}\right)
$$

where $\mathbf{S}$ is the overlap matrix and $\mathbf{P}^{\alpha-\beta}$ is the excess-spin density matrix, which for SCF or DFT may be written as

$$
\mathbf{P}^{\alpha-\beta}=\mathbf{C}^{\alpha} \widetilde{\mathbf{C}}^{\alpha}-\mathbf{C}^{\beta} \widetilde{\mathbf{C}}^{\beta}
$$

The $\mathbf{C}^{\alpha}\left(\mathbf{C}^{\beta}\right)$ are the occupied orbitals, arranged in $N_{\alpha}\left(N_{\beta}\right)$ row vectors with the dimensions of the atomic set $(N)$. The excess spin natural orbitals are obtained by solving the eigenvalue equation

$$
\left(\mathbf{S}^{1 / 2} \mathbf{P}^{\alpha-\beta} \mathbf{S}^{1 / 2}\right) \mathbf{V}=\Lambda \mathbf{V}
$$

with the excess occupation numbers in $\Lambda$ :

$$
\sum_{j} \Lambda_{j j}=N^{\alpha}-N^{\beta}
$$

$\Lambda_{j j}>0$ indicates an $\alpha$ spin excess; $\Lambda_{j j}<0$ a $\beta$ spin excess. The diagonal elements of $\Lambda$ are excess-spin occupation numbers and their absolute value can be used as a criterion to sort the 
relevant orbitals contributing to the spin polarization. It is easily verified that at least $N^{\alpha}-N^{\beta}$ eigenvalues equal to 1 are always obtained. The corresponding eigenvectors are used to evaluate the energy gaps as discussed in the text. These orbitals are identical to the UNO orbitals of Bofill and Pulay. ${ }^{35}$ It is also possible to show that in the special case of Restricted orbitals (again $N_{\alpha}>N_{\beta}$ ) one has

$$
\mathbf{P}^{\alpha}=\mathbf{P}^{\beta}+\mathbf{C}_{o}^{\alpha} \widetilde{\mathbf{C}}_{o}^{\alpha}
$$

$\mathbf{C}_{o}^{\alpha}$ being the rectangular $N \times\left(N_{\alpha}-N_{\beta}\right)$ orbital coefficient matrix for the singly occupied orbitals. Note that in this case $N_{\alpha}-N_{\beta}$ eigenvalues of Equation 3 are equal to one, while the others are equal to zero.

The whole procedure can be straightforwardly applied to the DFT calculations.

\section{Acknowledgment.}

RP thanks the National Science Foundation (CHE-9508521) for support. We are grateful to Prof. Cary Miller for the use of his DEC Alphastation 250 at the University of Maryland, which was purchased with the NSF grant CHE-9417357.

\section{References and Notes.}

${ }^{1}$ (a) Poli, R. Chem. Rev., 1996, 96, 2135 and references therein.

${ }^{2}$ (a) Anet, F. A. L.; Leblanc, E. J. Am. Chem. Soc., 1957, 79, 2649. (b) Fischer, E. O.; Ulm, K.; Kuzel, P. Z. anorg. allg. Chem., 1963, 319, 253. (c) Grohmann, A.; Köhler, F. H.; Müller, G.; Zeh, H. Chem. Ber., 1989, 122, 897. (d) Theopold, K. H. Acc. Chem. Res., 1990, 23, 263.

${ }^{3}$ (a) Grebenik, P. D.; Green, M. L. H.; Izquierdo, A.; Mtetwa, V. S. B.; Prout, K. J. Chem. Soc., Dalton Trans. 1987, 9. (b) Krueger, S. T.; Poli, R.; Rheingold, A. L.; Staley, D. L. Inorg. Chem., 1989, 28, 4599. (c) 
Krueger, S. T.; Owens, B. E.; Poli, R. Inorg. Chem., 1990, 29, 2001. (d) Abugideiri, F.; Kelland, M. A.; Poli, R.; Rheingold, A. L. Organometallics, 1992, 11, 1303. (e) Poli, R. J. Coord. Chem. B, 1993, 29, 121 and references therein.

${ }^{4}$ Fettinger, J. C.; Mattamana, S. P.; Poli, R.; Rogers, R. D. Organometallics, 1996, 15, 4211.

${ }^{5}$ Connor, J. A. Top. Curr. Chem., 1971, 71, 71.

${ }^{6}$ See e.g. McWeeny, R. Methods of Molecular Quantum Mechanics, Academic Press: London, Second Edition, 1978.

${ }^{7}$ See e.g. Parr, R. G. and Yang, W., Density Functional Theory of Atoms and Molecules, Oxford Univ. Press: Oxford, 1989.

${ }^{8}$ (a) Langhoff, S. R.; Bauschlicher, Jr., C. W. Ann. Rev. Phys. Chem., 1988, 39, 181-212.; (b) The challenge of $d$ and felectrons, theory and computation, Salahub, D. R.; Zerner, M. C. Eds.; ACS Symposium Series 394, American Chemical Society; Washington DC, 1989.

${ }^{9}$ (a) Density Functional Methods in Chemistry, Labanowski, J. K.; Andzelm, J. W., Eds., Springer: New York, 1991.; (b) Ziegler, T., Chem. Rev., 1991, 91, 651.

${ }^{10}$ Cacelli, I.; Keogh, D. W.; Poli, R.; Rizzo, A. New J. Chem., 1997, 21, 133.

${ }^{11}$ Poli, R.; Krueger, S. T.; Abugideiri, F.; Haggerty, B. S.; Rheingold, A. L. Organometallics, 1991, 10, 3041.

12 (a) Laird, B. B.; R. B. Ross; Ziegler, T. ACS Symp. Ser., 1996, 629, 1. (b) Bérces, A.; Ziegler, T. Topics in Current Chemistry, 1996, 182, 41. (c) Dickson, R. M.; Ziegler, T. J. Phys. Chem., 1996, 100, 5286. (d) Li, J.; Schreckenbach, G.; Ziegler, T. Inorg. Chem., 1995, 34, 3245. (e) Deng, L.; Margl, P.; Ziegler, T. J. Am. Chem. Soc., 1997, 119, 1094-1100.

${ }^{13}$ (a) Ricca, A.; Bauschlicher, C. W. Jr. J. Phys. Chem., 1995, 99, 5922; (b) Ricca, A.; Bauschlicher, Jr., C. W. Theor. Chim. Acta, 1995, 92, 123-131.

${ }^{14}$ (a) Wakatsuki, Y.; Koga, N.; Werner, H.; Morokuma, K. J. Am. Chem. Soc., 1997, 119, 360-366; (b) Musaev, D. G., Froese, R. D. J.; Svensson, M.; Morokuma, K. . J. Am. Chem. Soc., 1997, 119, 367-374.; and references therein.

${ }^{15}$ (a) Fiedler, A.; Schröder, D.; Schwarz, H.; Tjelda, B. L.; Armentrout, P. B. J. Am. Chem. Soc., 1996, 118, 5047-5055; (b) Heinemann, C.; Schwarz, J.; Schwarz, H. J. Phys. Chem., 1996, 100, 6088-6092; (c) Holthausen, M. C.; Fiedler, A.; Schwarz, H.; Koch, W. J. Phys. Chem., 1996, 100, 6236-6242; (d) Heinemann, C.; Schwarz, H.; Koch, W. Mol. Phys., 1996, 89, 473. 
${ }^{16}$ Su, M.-D.; Chu, S.-Y. Organometallics, 1997, 16, 1621-1627.

${ }^{17}$ Schmid, R.; Herrmann, W. A.; Frenking, G. Organometallics, 1997, 16, 701-708.

${ }^{18}$ Frisch, M. J.; Trucks, G. W.; Schlegel, H. B.; Gill, P. M. W.; Johnson, B. G.; Robb, M. A.; Cheeseman, J. R.; Keith, T. A.; Petersson, G. A.; Montgomery, J. A.; Raghavachari, K.; Al-Laham, M. A.; Zakrzewski, V. G.; Ortiz, J. V.; Foresman, J. B.; Cioslowski, J.; Stefanov, B. B.; Nanayakkara, A.; Challacombe, M.; Peng, C. Y.; Ayala, P. Y.; Chen, W.; Wong, M. W.; Andres, J. L.; Replogle, E. S.; Gomperts, R.; Martin, R. L.; Fox, D. J.; Binkley, J. S.; Defrees, D. J.; Baker, J.; Stewart, J. P.; Head-Gordon, M.; Gonzales, C.; Pople, J. A. Gaussian 94 (Revision A1); Gaussian Inc., Pittsburgh, PA, 1995.

${ }^{19}$ Møller, C.; Plesset, M. S. Phys Rev., 1934, 46, 618.

${ }^{20}$ Dunning, T. H., Jr.; Hay, P. J. in Modern Theoretical Chemistry, H. F. Schaefer III, Ed., Plenum Press: New York, 1976; p. 1.

${ }^{21}$ (a) Hay, P. J.; Wadt, W. R. J. Chem. Phys., 1985, 82, 270. (b) Wadt, W. R.; Hay, P. J. J. Chem. Phys., 1985, 82, 284. (c) Hay, P. J.; Wadt, W. R. J. Chem. Phys., 1985, 82, 299.

${ }^{22}$ Becke, A. D. Phys. Rev. A, 1988, 38, 3098.

${ }^{23}$ Slater, J. C., Quantum Theory of Molecular Solids. Vol. 4: the Self-Consistent Field for Molecules and Solids, Mc Graw Hill: New York, 1974.

${ }^{24}$ Lee, C.; Yang, W.; Parr, R. G. Phys. Rev. B, 1988, 37, 785.

${ }^{25}$ Becke, A. D. J. Chem. Phys., 1993, 98, 5648.

${ }^{26}$ (a) Pople, A. J.; Head-Gordon, M.; Fox, D. J.; Raghavachari, K.; Curtiss, L. A. J. Chem. Phys., 1989, 90, 5622.; (b) Curtiss, L. A.; Jones, C.; Trucks, G. W.; Raghavachari, K.; Pople, J. A. J. Chem. Phys., 1990, 93, 2537.

${ }^{27}$ Vrieze, K.; van Leeuwen, P. W. N. M. Progr. Inorg. Chem., 1971, 14, 1.

${ }^{28}$ Albright, T. A.; Burdett, J. K.; Whangbo, M. H. Orbital Interactions in Chemistry, Wiley: New York, 1985.

${ }^{29}$ Kohn, W.; Sham, L. J. Phys. Rev., 1965, 140, A1133.

${ }^{30}$ Dreizler, R. M.; Gross, E. K. U. Density Functional Theory. An Approach to the Quantum Many-Body Problem, Springer-Verlag: Berlin, 1990.

${ }^{31}$ Kubacek, P.; Hoffmann, R.; Havlas, Z. Organometallics, 1982, 1, 180.

${ }^{32}$ Lin, Z.; Hall, M. B. Organometallics, 1993, 12, 19.

${ }^{33}$ Simpson, C. Q., II; Hall, M. B.; Guest, M. F. J. Am. Chem. Soc., 1991, 113, 2898. 
${ }^{34}$ Pople, J. A.; Nesbet, R. K. J. Chem. Phys., 1959, 22, 571.

35 J. M. Bofill, X.; Pulay, P. J. Chem. Phys., 1989, 90, 3637. 